\title{
Additional records and stratigraphic distribution of the middle Eocene carettochelyid turtle Anosteira pulchra from the Uinta Formation of Utah, North America
}

\author{
Brent Adrian $^{\text {Corresp., } 1}$, Patricia A. Holroyd ${ }^{2}$, J. Howard Hutchison ${ }^{2}$, K.E. Beth Townsend ${ }^{1}$ \\ ${ }^{1}$ Department of Anatomy, Midwestern University, Glendale, Arizona, United States \\ 2 Museum of Paleontology, University of California, Berkeley, Berkeley, California, United States \\ Corresponding Author: Brent Adrian \\ Email address: badria@midwestern.edu
}

Background. Anosteira pulchra is one of two species of the obligately-aquatic freshwater clade Carettochelyidae (pig-nosed turtles) from the Eocene of North America. Anosteira pulchra is typically rare in collections, and their distribution is poorly documented. The Uinta Formation [Fm.] contains a diverse assemblage of turtles from the Uintan North American Land Mammal Age. Whereas turtles are abundantly preserved in the Uinta Fm., A. pulchra has been reported only from a few specimens in the Uinta C Member.

Methods. We describe new records of Anosteira pulchra from the Uinta Basin and analyze the distribution of 95 specimens from multiple repositories in the previously published stratigraphic framework of the middle and upper Uinta Fm.

Results. Here we report the first records of the species from the Uinta B interval, document it from multiple levels within the stratigraphic section and examine its uncommon appearance in only approximately $5 \%$ of localities where turtles have been systematically collected. This study details and extends the range of $A$. pulchra in the Uinta Fm. and demonstrates the presence of the taxon in significantly lower stratigraphic layers. These newly described fossils include previously unknown elements and associated trace fossils, with new anatomical information presented. This study provides insight into the taxonomy of Anosteira spp. in the middle Eocene, and suggests the presence of a single species, though no synonymy is defined here due to limits in Bridger material. 


\section{Additional records and stratigraphic distribution of}

2 the middle Eocene carettochelyid turtle Anosteira

\section{3 pulchra from the Uinta Formation of Utah, North}

\section{America}

5

6 Brent Adrian ${ }^{1}$, Patricia A. Holroyd ${ }^{2}$, J. Howard Hutchison ${ }^{2}$, K.E. Beth Townsend ${ }^{1}$

7

$8{ }^{1}$ Department of Anatomy, Midwestern University, Glendale, Arizona, USA

$9 \quad 2$ Museum of Paleontology, University of California, Berkeley, California, USA

10

11 Corresponding Author:

12

Brent Adrian ${ }^{1}$

13

19555 North 59 th Avenue, Glendale, Arizona, 85308, USA

Email address: badria@midwestern.edu 


\section{Abstract}

24 Background. Anosteira pulchra is one of two species of the obligately-aquatic freshwater clade 25 Carettochelyidae (pig-nosed turtles) from the Eocene of North America. Anosteira pulchra is 26 typically rare in collections, and their distribution is poorly documented. The Uinta Formation 27 [Fm.] contains a diverse assemblage of turtles from the Uintan North American Land Mammal 28 Age. Whereas turtles are abundantly preserved in the Uinta Fm., A. pulchra has been reported 29 only from a few specimens in the Uinta C Member.

30 Methods. We describe new records of Anosteira pulchra from the Uinta Basin and analyze the

31 distribution of 95 specimens from multiple repositories in the previously published stratigraphic 32 framework of the middle and upper Uinta Fm.

33 Results. Here we report the first records of the species from the Uinta B interval, document it 34 from multiple levels within the stratigraphic section and examine its uncommon appearance in 35 only approximately $5 \%$ of localities where turtles have been systematically collected. This study 36 details and extends the range of A. pulchra in the Uinta Fm. and demonstrates the presence of the 37 taxon in significantly lower stratigraphic layers. These newly described fossils include previously unknown elements and associated trace fossils, with new anatomical information presented. This study provides insight into the taxonomy of Anosteira spp. in the middle Eocene, and suggests the presence of a single species, though no synonymy is defined here due to limits 41 in Bridger material.

\section{Introduction}

The Uinta Formation [Fm.] in the Uinta Basin of northeastern Utah (Fig. 1) contains a 
46 Mammal Age (NALMA). Anosteira is a genus of small to medium-sized highly aquatic

47 freshwater turtles belonging to Carettochelyidae (Gill, 1889) that apparently emigrated from Asia

48 to North America during the early Bridgerian NALMA (Hutchison, 1998). Two North American

49 species of the genus have been described to date. The older of the two, Anosteira ornata, is

50 known from several Bridgerian sites in southwest Wyoming (see Joyce, 2014 for a recent

51 summary). Gilmore (1916) provisionally reported A. ornata in Uinta C based on CM 2954,

52 collected on the White River near Ouray, Utah. Clark (1932) named Pseudanosteira pulchra

53 based on CM 11808 from the Uinta C horizon at Leota Ranch, northwest of Ouray, Utah, but did

54 not mention CM 2954. Broin (1977) recombined P. pulchra as A. pulchra, noting the

55 differentiation of Pseudanosteira from Anosteira on the shape of the anterior neurals, but

56 reduction of the vertebral scales was not supportable in the absence of data on individual and

57 specific variability. This synonymy was followed by Joyce (2014), Joyce, Volpato \& Rollot

58 (2018), and is followed here. Joyce (2014) noted the potential range extension represented by

59 CM 2954 but did not elect to make a species assessment. As the literature currently stands, only

60 two carettochelyid specimens have been noted or described from the Uinta Basin. Both occur in

61 the upper part of the Uinta Fm., in beds historically referred to Horizon C or Uinta C, and may

62 represent two different species. However, targeted collecting in recent years of Uintan

63 herpetofauna in a measured stratigraphic framework has yielded 95 carettochelyid specimens,

64 none of which have previously been described. The aim of this study is to describe the

65 stratigraphic and geographic distribution of A. pulchra in the Uinta Fm. and provide new

66 anatomical information on its morphology.

67

68 Geological Setting 
The Uinta Basin in northeastern Utah (Fig. 1) is approximately 135 miles wide along its

70

71

72 73

74 75

east-west axis and 100 miles across from north to south, encompassing an area of $10,943 \mathrm{~km}^{2}$

(Ryder, Fouch \& Elison, 1976; Prothero, 1996; Murphey et al., 2011). Its boundaries include the Uinta Mountains to the north, the Book Cliffs/Tavaputs Plateau to the south, the Douglas Creek Arch and Roan Plateau to the east, and the Wasatch Range to the west (Murphey et al., 2011)

(Fig. 1). Over 4,500 $\mathrm{m}$ of Eocene sediments accumulated during the Laramide orogenesis, filling the Uinta, Green River, and Piceance Creek basins (Prothero, 1996; Murphey et al., 2011).

These sediments record part of a vast system of middle Eocene lakes that covered a large portion of northeastern Utah, southwestern Wyoming, and western Colorado (Ryder, Fouch \& Elison, 1976; Prothero, 1996; Murphey et al., 2011; Chamberlain et al., 2012).

During the Bridgerian NALMA (47-49 Ma), the Green River lake system began to recede, replacing lacustrine shales with fluvial-deltaic mudstones and sandstones which now comprise a rich matrix for terrestrial fossil vertebrates (Murphey et al., 2011). In the Uinta Basin, the fluvial Uinta Fm. gradually replaced the Green River lake system, beginning at the east end of the basin (Fig. 1). As a result, the lower fluvial sandstones of the eastern Uinta Fm. are laterally equivalent to lacustrine evaporates, sandstones, and limestones in the western Uinta Basin, and the two units share complex interfingering (Dane, 1954, 1955; Ray, Kent \& Dane, 1956; Cashion, 1967; Ryder, Fouch \& Elison, 1976). The primary focus of this study is to describe the stratigraphic distribution of Anosteira pulchra in the eastern Uinta Fm., but we also record some additional western occurrences (Fig. 1).

The Uinta Fm. is the highly fossiliferous type formation of the Uintan NALMA (Wood et al., 1941; Prothero, 1996) (Figs. 1, 2A). The study area lies between latitudes $40^{\circ} 00^{\prime}$ and $40^{\circ} 30^{\prime}$ north and longitudes $109^{\circ} 00^{\prime}$ and 10945' west (Townsend, Friscia \& Rasmussen, 2006) (Fig. 
92 1). Most of the localities discussed here are tied to a stratigraphic section described by

93 Townsend, Friscia \& Rasmussen (2006) that extends $366 \mathrm{~m}$ through the older Uinta B (0-137 m)

94 into the younger Uinta C (140-366 m), resulting in the first known conformable contact between

95 the Uinta and Duchesne River Formations at $366 \mathrm{~m}$ (Osborn, 1895, 1929; Prothero, 1996;

96 Townsend, Friscia \& Rasmussen, 2006) (Fig. 2A). Gunnell et al. (2009) divided the Uintan

97 NALMA into four biochronological zones (Ui1a, Ui1b, Ui2, Ui3) on the basis of mammalian

98 biostratigraphy of the Uinta, Bridger, and Washakie Formations. Material in the current study

99 occurs in the immediate area of the stratotype localities for biochrons Ui2 and Ui3 or can be

100 stratigraphically correlated with them (Gunnell et al., 2009; Townsend et al., 2010; Smith et al.,

101 2017, 2020; Stidham, Townsend \& Holroyd, 2020) (Fig. 2).

102 Only one turtle (Baena inflata) is reported from Uinta A, while Uinta B and C combined 103 contain all other reported taxa (Gilmore, 1916). Baena inflata has been grouped with "Baena"

104 affinis (Leidy, 1871), which was reestablished by Joyce \& Lyson (2015), but a recent survey of

105 Uintan baenids was unable to find additional material referable to the species (Smith et al.,

106 2017). Uinta A has often been mistaken for the lower levels of Uinta B, and many workers have

107 concluded that the lowest approximately 150 meters of the formation does not bear fossils

108 (Osborn, 1895; Riggs, 1912; Osborn, 1929; Prothero, 1996).

109

Materials \& Methods

We used measured stratigraphic sections from Townsend, Friscia \& Rasmussen (2006),

112 which were recorded during the summers of 1997, 1998, 2000, and 2014. Fossil collection and

113 stratigraphic work was conducted in a restricted area of the eastern Uinta Basin, on public land

114 administered by the Bureau of Land Management (Paleontological Resources Use Permit

Peer] reviewing PDF | (2020:06:49966:1:2:NEW 27 Jul 2020) 
115 Number UT06-031S). This study also includes published specimens from the Carnegie Museum

116 of Natural History and the Yale Peabody Museum of Natural History and examines previously

117 unpublished specimens from Brigham Young University Museum of Paleontology, the Natural

118 History Museum of Utah, and the Utah Field House of Natural History State Park Museum.

119 Collections from the latter three museums were integrated into the measured stratigraphy of

120 Townsend, Friscia \& Rasmussen (2006) from locality data on file at each repository. Additional

121 records have been included from the University of California Museum of Paleontology from

122 elsewhere in the basin, but these cannot be included in the detailed stratigraphic framework.

123 Measurements of fossil specimens were taken using Mitutoyo Absolute Digimatic digital

124 calipers, and from high quality digital images using ImageJ software (Rasband, 1997-2016).

125 Magnified photos were produced using an Olympus SZX7 stereo microscope. Unless otherwise 126 specified, all measurements are in millimeters $(\mathrm{mm})$, recorded to the nearest $0.01 \mathrm{~mm}$ and

127 rounded to the nearest $0.1 \mathrm{~mm}$. Nomenclature for vertebral scales conforms to that proposed by 128 Danilov et al. (2017).

129 Institutional Abbreviations

130 BYU Brigham Young University Museum of Paleontology, Provo, Utah, USA

131 CM Carnegie Museum of Natural History, Pittsburgh, Pennsylvania, USA

132 MWU Midwestern University, Glendale, Arizona, USA

133 UCMP University of California Museum of Paleontology, Berkeley, California, USA

134 UFH Utah Field House of Natural History State Park Museum, Vernal, Utah, USA

135 UMNH.VP Vertebrate Paleontology Collection, Natural History Museum of Utah, Salt Lake $136 \quad$ City, Utah, USA

137 WU Washington University, St. Louis, Missouri, USA 
138 YPM VPPU Princeton University collection in the Division of Paleontology, Yale Peabody 139 Museum of Natural History, New Haven, Connecticut, USA

140

141

142 peripheral, $\mathbf{p y}=$ pygal, $\mathbf{s p}=$ suprapygal
143

\section{Systematic Paleontology}

145 TESTUDINES Batsch, 1788

146 CRYPTODIRA Cope, 1868

147 TRIONYCHIA Hummel, 1929

148 CARETTOCHELYIDAE Gill, 1889

149 ANOSTEIRA Leidy, 1871

150 Anosteira pulchra (Clark, 1932)

151 Figures 3-6; Tables 1-2

152 Synonymy. Pseudanosteira pulchra (Clark, 1932)

153 Holotype. CM 11808, a complete carapace, nearly complete hyoplastra, hypoplastra, and anterior 154 extremities of posterior plastral lobe.

155 Newly Referred Specimens. Table 1 contains 95 previously undescribed specimens recovered 156 from the measured stratigraphic section of Townsend, Friscia \& Rasmussen (2006). The

157 minimum numbers of individuals, based on the maximum number of individual elements at each 158 locality, is 37 (see Discussion). 
159 Type Locality and Horizon. Quarry L, Leota Ranch, near village of Ouray, Uinta County, Utah,

160 USA (Clark, 1932, figure 7). Upper Horizon C (Clark, 1932:161), Uinta Formation, Lutetian,

161 middle Eocene.

162 Description

163 Due to the large sample size in this study, the specimens described below were selected as

164 representative elements of $A$. pulchra found within the measured stratigraphic section of

165 Townsend, Friscia \& Rasmussen (2006).

166 Carapace (Fig. 3)

167 UMNH.VP.27632 is an anterior carapace margin that includes the nuchal and left first 168 peripheral (Fig. 3A-B). There is a midline protuberance approximately $7 \mathrm{~mm}$ wide and $5 \mathrm{~mm}$

169 long that is raised $1.5 \mathrm{~mm}$ above the dorsal surface of the carapace, occupying most of the

170 midline space between the anterior free margin and the intervertebral sulcus between the fused

171 cervical/vertebral 1 and vertebral 2 scales (Fig. 3A). The protuberance forms the anterior limit of

172 the dorsal keel, and a rounded dorsal projection is the most robust point along the thickened

173 margin of the nuchal embayment (Fig. 3A). The anterior extremities of the sulci forming the

174 slightly sigmoidal lateral sides of vertebral scale 2 project posteriorly from the aforementioned

175 intervertebral sulcus (Fig. 3A). The sulci of this element are generally thin $(<0.5 \mathrm{~mm})$ and finely

176 incised (Fig. 3A). Dorsal surface sculpture consists of a network of grooves that are roughly

177 parallel to the free margin of the carapace (Fig. 3A). Grooves are shorter, more clustered, and

178 have more pronounced relief where the periphery changes direction, as at peripheral 1 (Fig. $3 A$ ).

179 The dorsal surface is quite smooth near the midline of the nuchal, where a slight ridge indicates

180 the beginning of the median keel (Fig. 3A). The ventral surface of UMNH.VP.27632 is smooth

181 except for finely toothed sutures between the specimen and adjacent bones (Fig. 3A-B). A pair of 
182 gracile projections extend from the internal surface of the carapace to articulate with cervical 183 vertebra 8 (Fig. $3 B$ ). Each projection is approximately $2.4 \mathrm{~mm}$ wide, $1 \mathrm{~mm}$ long, and $1.7 \mathrm{~mm}$ 184 tall, crescent-shaped, and concave posteriorly (Fig. 3B). UMNH.VP.31059 (Fig. 3C) and UMNH.VP.27146 (Fig. 3D-F) are partial anterior neural rows of $A$. pulchra, with a characteristic anterior spike in the midline carina (keel) arising from neurals 3 and 4 (Fig. 3C-D). The spike falls sharply in the posterior third of neural 4, returning 188 to approximately the same maximum height as the midpoint of neural 4 (Fig. 3C-D). In dorsal and ventral views of UMNH.VP.27146, neural 2 is pentagonal and uniformly wide, and neurals 3-6 are hexagonal, wider anteriorly, and have short anterior sides (Fig. 3E-F). Neural 5 of UMNH.VP.27146 is missing (Fig. 3D-F), though the keel of neural 6 was likely similar in height 192 (Fig. 3D). 6 and 7, suprapygal, and pygal), as well as peripheral 8 described below (Fig. $3 Y$-AA). Neural 6 is generally rectangular dorsally, measuring $7.5 \mathrm{~mm}$ long and $4.2 \mathrm{~mm}$ wide (Fig. $3 G-H)$. Neural 7 is proportionally shorter, and is $8.1 \mathrm{~mm}$ long and $6.2 \mathrm{~mm}$ wide (Fig. 3G-H). The dorsal outline 197 of neural 7 is distinctly hexagonal, and its surface area is larger dorsally than ventrally (Fig. 3G$H$ ). Both posterior neurals have a smooth dorsal surface, and the posterior keel of neural 6 is warped slightly laterally (Fig. 3G). The keel of neural 6 is triangular in profile and forms a second spike behind that of neural 4 , rising approximately $3 \mathrm{~mm}$ above the external surface (Fig. 3I). Midline parts of UMNH.VP.30590 are missing between the posteriormost neurals and suprapygal (Fig. 3G-L). The eighth costals are missing, but meet at the midline in situ in complete specimens (see Clark, 1932). A tightly beaded pattern covers the dorsal and ventral surfaces of the pygal posterior to the anterior ventral embankment (Fig. 3J-L). The posterior 
205 pygal margin is acute, similar to the posterior peripherals, but is thickest at the midline (Fig. $3 \mathrm{~J}$ -

$206 L, A A)$. The pygal has a midline sulcus along the dorsal surface, as described above (Fig. 3J). A

207 low keel bisects the suprapygal along the dorsal midline, and the ventral surface of the

208 suprapygal is smooth and slightly concave (Fig. $3 J-K)$. The suture between the suprapygal and

209 pygal is finely dentate (Fig. $3 K$ ), and the pygal flares posteriorly and dorsally (Fig. 3J-L).

210 UMNH.VP.19951 is a right costal 1 that is missing two sections of its posterior edge

211 (Fig. 3M-N). It has a length of $21.9 \mathrm{~mm}$ and a width of $41.2 \mathrm{~mm}$. Its posterior suture is concave

212 anteriorly, and its anterior margin convex, where it is sutured for articulation with the nuchal and

213 the first three peripherals (Fig. 3.M-N). The medial and lateral sutures are preserved, indicating

214 articulation with neural 1 and the anterior portion of peripheral 3, respectively (Fig. $3 N$ ). The

215 bone is thinnest near its middle, and the head of the first rib is separated from the medial suture

216 and flanked by several small foramina (Fig. $3 N$ ). Otherwise, the ventral surface is smooth, and

217 the dorsal surface shows little evidence of texture apart from a few oblong pits and small gouges

218 (Fig. 3M).

219

UMNH.VP.31058 is a right peripheral 2 that has the characteristic flattened cylindrical

220

221

222

223

224

225

226

227

shape of the anteriormost peripherals (Fig. 3O-Q). Its lateral edge is straight (Fig. 3O-P), and the lateral margin is rounded in cross section (Fig. 3Q). No sulci are present, and a finely pitted texture is present only in dorsal view (Fig. 3O). The surface becomes smooth along the lateral edge and ventral view of the bone (Fig. 3P).

UMNH.VP.27077 is a left peripheral 3 that is missing its anteromedial corner (Fig. $3 R$ -

S). Its ventral surface is smooth (Fig. 3S), and its dorsal surface is slightly rugose and damaged by two large, irregular pits near the lateral edge (Fig. 3R). The posterolateral margin projects ventrally and there are two prominent sockets that mark articulation with the hyoplastron and the 
228 beginning of the bridge series of peripherals (Fig. 3S). The anterior half of the lateral margin 229 maintains the flattened cylindrical character of the peripherals anterior to it, but the edge slopes 230 sharply ventrally as it forms the seat of the axillary buttress of the bridge (Fig. S-T).

231 UMNH.VP.27077 also includes a left peripheral 6 with robust gomphotic sockets that 232 characterize bridge peripherals (Fig. 3U-X). Anteriorly, peripherals are thin and rod-like (Fig. $2333 O-Q$ ), become thick and triangular in the bridge region (Fig. 3R-X), and are wide and flat 234 posteriorly (Fig. 3Y-AA). Peripheral 8, associated with other elements from UMNH.VP.30590 235 described above (Fig. 3G-L), is an example of the broad, flat, acutely-margined posterior 236 peripherals (Fig. 3Y-AA). It is $19.2 \mathrm{~mm}$ long, $18.1 \mathrm{~mm}$ wide, and $9.77 \mathrm{~mm}$ tall, and only its 237 dorsal surface is sculptured (Fig. 3Y). An intermarginal sulcus crosses the dorsal surface 238 transversely at its anterior third (Fig. 3Y), and a longitudinal, rounded embankment tapers 239 posteriorly along the medial side of the ventral surface (Fig. 3Z).

240 To summarize, peripherals articulate to form a slightly flaring, often scalloped ring whose 241 most distal parts are thin and delicate (Figs. 3Y-AA, 6B, D). Distinct gomphoses indicate clear 242 articulations between bridge peripherals 3-7 and adjacent bones of the carapace and plastron 243 (Fig. 3T, X), while anterior peripherals 1-2 and posterior peripherals 8-10 only articulate with the 244 carapace (Fig. 3Q, $A A$ ). The angle formed by the dorsal and ventral faces at the lateralmost edge 245 of the shell is approximately $66.5^{\circ}$ in peripheral 6 (Fig. $3 X$ ), but becomes acute to approximately $24628^{\circ}$ in the posterior peripherals (Fig. $3 A A$ ). A distinct median dorsal carina (keel) forms a blunt, 247 posteriorly-oriented spike on neurals 3-4 (Clark, 1932) (Fig. 3C-E). The carina continues 248 posteriorly and terminates on the antero-dorsal view of the pygal as a distinctly raised midline 249 ridge anterior to the confluence of the marginal scales (Fig. 3J). The pygal is robust and 250 trapezoidal $($ Fig. $3 J-K)$. It has a pronounced embankment perpendicular to the midline in antero- 
251 ventral view, as in all carettochelyids, forming a posterior wall of the body cavity (Havlik, Joyce

252 \& Böhme, 2014; Joyce, 2014) (Fig. 3K-L).

253 Plastron (Fig. 4)

254

255

256

257

258

259

260

261

262

263

264

265

266

267

268

269

270

271

272 suture is visible along the bone's anteromedial edge, where the bone is thinnest $(2.9 \mathrm{~mm})$ (Fig.

$2734 C-D$ ). The sutures of this area are better preserved in the smaller left hypoplastron 
274 UMNH.VP.26554 (Fig. 4E-G) and the sutures shared with adjacent bones are intact (Fig. 4E-G).

275 In UMNH.VP.26554, the hyo-hypoplastral suture and the midline form an approximately $73^{\circ}$

276 angle (Fig. 4E, G). The width of the left hypo-xiphiplastral suture is $12.39 \mathrm{~mm}$ and the plastron

277 has a maximum thickness of $6.2 \mathrm{~mm}$ (Fig. 4E-G). The partial right hypoplastron

278 UMNH.VP.26917 is $24.2 \mathrm{~mm}$ long and $14.8 \mathrm{~mm}$ wide (Fig. $4 H-I$ ). Its ventral surface has

279 perhaps the clearest defined texture of all the plastra examined in this study (Fig. 4H). On it, 280 there is a series of four distinct, nearly parallel trace marks on the ventral surface of

281 UNMH.VP.26917, immediately anterior to the hypo-xiphiplastral suture (Figs. 4H, 5). These are 282 are shown magnified in Figure 5, interpreted and discussed below. $\mathrm{mm}$ wide (Fig. 4J-M). The bone is narrow and its lateral edge is nearly parallel to the midline, but its posterior quarter tapers to a point (Fig. $4 \mathrm{~J}-\mathrm{K}$ ) indicating the lack of anal notch as in other Anosteira spp. The hypo-xiphiplastral suture is sinusoidal, and the articular surface along the suture is comprised of a complex network of gomphotic scarph pegs and sockets (Fig. 4J-M). It is generally even in thickness, but is thickest anteriorly along the midline (Fig. $4 L$ ). The bone bends dorsally and its posterior point forms a distinct spike with several longitudinal ridges on the dorsal surface (Fig. $4 K$ ). Both the dorsal and ventral surfaces are mostly smooth, and several small foramina are present in the anterior half of the dorsal side (Fig. 4K). A narrow groove runs

293 This groove probably marks the limit of the skin contact on the dorsal surface.

\section{An associated carapace and plastron (UMNH.VP.31072) (Fig. 6)}


297 2-6 and adjacent costals (Fig. 6A, C), along with a peripheral ring that is missing only the left 298 peripheral 3, right peripheral 5, and significant portions of bilateral peripherals 4 and 8 (Fig. $6 B$, $299 D$ ). Neurals 1 and 7 are missing, though most of the suprapygal is preserved including its midline 300 keel (Fig. 6A, C). Apart from the medial portions which articulate with the neural series (Fig. 6A, 301 C), the costals were fractured into dozens of tiny fragments from the middle of the bones. 302 The plastron of UMNH.VP.31072 is well preserved, missing only the anterior half of the 303 right xiphiplastron, approximately the posterior third of the left xiphiplastron, and lateral portions 304 of the bilateral hyoplastra (Fig. $6 B, D$ ). The anterior plastral lobe is represented by one fragment 305 of the epiplastron which articulates with the curved anteromedial margin of the hyoplastron (Fig. 306 $6 B, D)$. This posterior portion of the right epiplastron is thickest along a ridge at the middle of

307 the width of the bone, and a narrow groove lies along the medial side of the ridge (Fig. 6B).

308 There are fine striations near the midline, anterior to the groove, possibly indicating ligamentous 309 articluation associated with the kinetic hinge at the epi-hyoplastral contact (Fig. 6B). The 310 remainder of the plastron is consistent with the specimens described above, and the preserved 311 right xiphiplastron tapers to a thickened point posteriorly, as in UMNH.VP.20525 (Fig. 4J-M).

312 This specimen is the most complete individual of Anosteira pulchra in the current study and 313 allows a simple estimation of the turtle's size. Using relative proportions from the type specimen 314 (CM 11808) (Fig. 7A), UMNH.VP.31072 is estimated to have a midline carapace length of 15.3 $\mathrm{cm}$, approximately $80 \%$ the size of CM 11808 .

\section{Results}

The 95 Anosteira pulchra specimens in this study (Table 1) substantially increase the sample of this taxon and provide new insights into its stratigraphic distribution in the Uinta 
320 Formation, which are discussed below. Uinta $\mathrm{C}$ contains most occurrences and the stratigraphic

321 range of the species is extended into older Uinta B sediments (Fig. 2).Additional Uintan records

322 of Anosteira pulchra from outside the study area are provided in Table 2. This set of specimens

323 cannot be correlated with the measured stratigraphy of Townsend, Friscia \& Rasmussen (2006),

324 but they demonstrate the presence of $A$. pulchra in other parts of the Uinta Basin, suggesting

325 areas worthy of further collecting and stratigraphic analysis. UCMP locality V98069 is near

326 Starvation Reservoir (Duchesne County, UT) and is partially surrounded by Uinta B and C strata

327 (Sprinkel, 2018) (Fig. 1). Localities V71057 and V71058 are northwest of Ouray (Uintah

328 County, UT), near Myton Pocket, and V98069 is near the study area, but not MWU localities

329 (Sprinkel, 2007) (Fig. 1).

330

331 Discussion

332 Distribution of Anosteira pulchra in the Uinta Formation

333 Two major facies can be described for both the lower and upper intervals of the Uinta

334 Fm. stratigraphic section. The lower intervals are typified by mud and claystone over-bank

335 deposits near fine-grained channel sandstones, with very little soil development ( 0 - 140 m;

336 Townsend, Friscia \& Rasmussen, 2006). The upper intervals (140-366 m) are characterized by

337 more mature paleosols, interspersed with channel sandstones composed of larger clasts and

338 stones, as well as some ponds (WU-26; Westgate et al., 2013). Specimens of Anosteira

339 pulchra are found in both facies types, and numerous specimens were recovered from both WU-

340134 and WU-26, localities in the upper intervals of the formation (Fig. 2B). Westgate et al.

341 (2013) determined that the WU-26 locality was very likely a pond, and although extensive

342 sedimentological study has not been performed at WU-134, a series of mature paleosols are 
343 present and further work may reveal that this was also a pond site. More specimens are certainly

344 associated with the upper intervals of the formation and localities with mature paleosol

345 development and there are fewer specimens from the lower intervals. It is not possible to

346 determine if this difference is an ecological preference of A. pulchra, or if it is a taphonomic bias

347 due to less over-bank flooding during the time of paleosol development preserved in the upper

348 intervals of the formation, which allowed for greater accumulation of skeletal elements.

349 Historically, most collecting in the Uinta Fm. has focused on mammals, and the most

350 frequently collected and most productive fossil mammal localities occur near the top and bottom

351 of the section (Townsend, Friscia \& Rasmussen, 2006; Townsend et al., 2010) (Fig. 2A). It is

352 noteworthy that nearly all of the specimens collected and examined in this study were collected

353 from the surface or by traditional excavation techniques. Material from four locations at

354 approximately $280 \mathrm{~m}$ (Fig. 2A) was screenwashed but produced no turtle fossils. Since 2007,

355 more than 25 tons of bulk sample have been excavated from deposits at $237 \mathrm{~m}$ (Murphey et al.,

356 2017). This work has yielded more than 400 mammal specimens identifiable to genus or species

357 (Westgate et al., 2013). Only one Anosteira pulchra specimen (UMNH.VP.26554) was

358 recovered via these means, providing additional evidence that the taxon is uncommon or patchy

359 in distribution, rather than common and under sampled.

360 The minimum number of the individuals (MNI) calculated from the 95 Anosteira pulchra

361 specimens reported in this study is 37 , based on the maximum number of individual elements at

362 each locality. Of the MNI, 78\% occur above $140 \mathrm{~m}$, in Uinta C sediments (Fig. 2A-B). The

363 maximum abundance occurs near $237 \mathrm{~m}$, stratigraphically between the Glen Bench Bed and

364 Sherbet Orange Bed (Fig. 2A-B). The most significant gap is between the base of this interval

$365(226 \mathrm{~m})$ and the Uinta B-C boundary $(137-140 \mathrm{~m})$ (Fig. 2A). This interval contains the upper $\mathrm{H}$ 
366

367

368

369

370

371

372

373

374

375

376

377

378

379

380

381

382

383

384

385

386

387

388

section strata (below 200 m), which includes the Ruby Red Wash, Red Wash Yellow, and Susan's Stripe Gray Marker Beds (Fig. 2A). The remaining 22\% of the MNI were found in Uinta $\mathrm{B}$ rocks, without a substantial peak as in higher strata. Occurrences of $A$. pulchra in Uinta B are more evenly distributed and have lower abundances than Uinta C. A gap in the uppermost Uinta B sediments near Devil's Playground $1(106-137 \mathrm{~m})$ is notable because this interval includes WU-117, a highly productive and well-sampled locality in the area. This suggests that the absence of $A$. pulchra fossils in the interval is not simply collection bias. Currently we have no sedimentologic explanation for the lack of $A$. pulchra in this 31 meter interval. Additional targeted collection in the future may reduce gaps, identify factors related to abundance, and clarify the trends reported here.

\section{Evidence of rodent gnaw marks on UMNH.VP.26917}

A hypoplastral fragment (UMNH.VP.26917) from 286 m (Uinta C) has four sets of linear excavations in the posterior half of its ventral surface, near the hypo-xiphiplastral suture (Figs. $4 H, 5)$. The shell fragment is $24.4 \mathrm{~mm}$ long and $14.8 \mathrm{~mm}$ wide, consistent with the size of an adult turtle (Fig. 4H). Each of the scratches has a thin puncture at its lateral end and several associated scrape marks which travel anteromedially across the bone to a maximum of $7.8 \mathrm{~mm}$ (Fig. 5). The scrape components are approximately perpendicular to the punctures and the ornamental ridges of the bone, nearly parallel and without intersection (Fig. 5). Scrapes are deepest near to the puncture and gradually become shallow medially, indicating they were initiated laterally. The middle two punctures are most prominent, with shapes that are slightly sinusoidal and mirrored across the gap between them. The portions of the puncture nearest the gap are widest and deepest, penetrating the cortex. The anterior edges of each scrape are sharp and their floors rough, suggesting they had not undergone repair (Fig. 5). 
The scratches are interpreted as gnaw marks inflicted by a rodent, consistent with

390

391

392

393

394 395

396

397

398

399

400

401

402

403

404

405

406

407

408

409

410

411

compression punctures and tapering scratches described on Eocene turtles by Hutchison \& Frye

(2001). Rodent gnaw marks can be differentiated from those of carnivorans by their

characteristic parallel series of furrows (Haglund, Reay \& Swindler, 1998; Pobiner, 2008). The

shape of the punctures indicates sharp flat teeth, consistent with rodent incisors, in addition to

their small size (1.4-1.7 mm wide). The notable gap between the middle two foci $(0.7 \mathrm{~mm})$

suggests lower incisors, which are sometimes not immediately adjacent due to the unfused

mandibular symphyses of rodents (Addison \& Appleton, 1915; Weijs, 1975). Rodents were

common in a variety of sizes in Uinta C of the Uinta Fm. (see Rasmussen et al., 1999), and the

tracemaker was relatively small.

\section{General remarks on shell structure and kinesis in Anosteira pulchra}

The two North American species of Anosteira (A. ornata Leidy, 1871 and A. pulchra

Clark, 1932) are distinguished from one another primarily by the shape of neurals and arrangement of vertebral scales (Hay, 1906; Clark, 1932; Hutchison, 1996; Joyce, 2014). Both

species of Anosteira (Clark, 1932) have a broadly ovate carapace with a shallow nuchal embayment (Hay, 1908; Clark, 1932) (Fig. 3A-B). The plastral morphology of Anosteira is similar to other trionychians, intermediate in size between the narrow, cruciform plastron of Kizylkumemys and the large plastron of the Carettochelyinae (Havlik, Joyce \& Böhme, 2014; Joyce, 2014). The plastra of Anosteira spp. (and all Carettochelyidae) exhibit no visible sulci, indicating that no plastral scales were present (Havlik, Joyce \& Böhme, 2014; Joyce, 2014) (Figs. 4, $6 B, D)$. Unlike Trionychidae, Anosteira features scales and sulci on the carapace, and has ten pairs of peripherals (Havlik, Joyce \& Böhme, 2014; Joyce, 2014) (Figs. 3, 6). The periphery of $A$. pulchra forms a robust structural ring around the margin of the carapace (Fig. 6B, D). Sutures 
412 between adjacent peripherals are generally articulated via fine dentate sutures, but many sutures

413 in the plastron show broader and more diffuse areas of soft tissue connection, indicative of

414 kinesis. Kinesis was possible between the epiplastra and entoplastron, the right and left side of

415 the hyo- and hypoplastra and xiphiplastra, a general pattern seen in other carettochelyids (e.g.,

416 Meylan, 1988; Meylan \& Gaffney, 1989; Hutchison, Holroyd \& Ciochon, 2004; Joyce et al.,

417 2012) and more generally in highly aquatic turtles (Bramble, 1974; Bramble, Hutchison \&

418 Legler, 1984; Angielczyk, Feldman \& Miller, 2010). The number of kinetic sutures and range of

419 motion primarily enabled the head and neck to be withdrawn under the carapace. Some flattening

420 of the shell and the accommodation of relatively enlarged fore flippers lateral to the shell were

421 likely also permitted.

422 Vertebral scale pattern variation in Anosteira pulchra

423 In general, carettochelyids exhibit a wide variety of scale patterns between genera,

424 species and even individuals, and the clade is sexual dimorphic in body size and posterior 425 plastral kinesis (Joyce, Parham \& Gauthier, 2004, 2012; Joyce, 2014; Danilov et al., 2017). The

426 partial carapace of UMNH.VP.27146 (Figs. 3E, 7E) provides a clear example of the most

427 common scale pattern recovered in the current study. All published accounts of Anosteira

428 pulchra (i.e., Clark, 1932; Gaffney, 1979; Havlik, Joyce \& Böhme, 2014; Joyce, 2014; Danilov et

$429 a l ., 2017)$ are based on the holotype (CM 11808), which is a nearly complete carapace and

430 plastron that is missing its entire anterior plastral lobe and most of the posterior lobe behind the

431 hypo-xiphiplastral suture (Fig. 7A). CM 11808 has a pair of vertebral scales (the second and a

432 coalesced third and fourth) that partly surround the anterior "additional vertebral" sensu Danilov

433 et al., (2017). They are figured with a gap between them that occupies much of the length of

434 costal 3 (see Clark, 1932) (Fig. 7B). An examination of the type specimen (CM 11808) reveals 
435 that Clark (1932) accurately figured the pattern traced on the type specimen in red (Fig. 7A).

436 However, except for UMNH.VP.31072, all fossil material discussed in the current study repeats

437 a pattern in which there is contact between vertebral scale 2 and combined vertebral scales 3 and 4384 (Figs. 3E, 7C-E). The degree of adjacency is apparently somewhat variable, as evident when 439 comparing the pattern of UMNH.VP.27146 (Fig. 7E) with two well-preserved carapaces (YPM 440 VPPU 016317 and 016318) from the 1936 Princeton Uinta Basin expedition (noted in Joyce, 441 2014) (Fig. 7C-D). The scute pattern of UMNH.VP.31072 is notable for lacking contact between 442 vertebral 2 and vertebrals $3+4$ (as in the type), and asymmetrical constriction of the posterior 443 extensions of vertebral 2 (Fig. 7H). However, contact between vertebrals 2 and $3+4$ and 444 sometimes slight lateral adjacency is the most frequently recovered variation (Fig. 7C-E). While 445 this study presents a modified scale arrangement from the type, it is consistent with the 446 homology and resulting discussion of carettochelyid phylogeny in Danilov et al. (2017). It is 447 unclear if the observed scale variation affected shell stability or is related to the broader 448 carettochelyid trend of scale reduction and eventual loss. In any case, the longitudinal expansion 449 of vertebral scales adjacent to the midline in A. pulchra is similar to that of A. ornata (Danilov et $450 a l ., 2017)$. The variability in scalation we find in the Uintan A. pulchra and similarity of neural 451 formula to A. ornata may suggest that this is a single species (as alluded to by Joyce (2014), 452 Havlik, Joyce \& Böhme (2014), and Joyce, Volpato \& Rollot (2018)) or a chronospecies. 453 However, until larger samples of $A$. ornata from the Bridger Fm. can be described and any 454 variation in these (or novel) features examined comparatively, we conservatively retain the two 455 species. In total, this study provides a robust account of the morphology of $A$. pulchra, examines 456 intraspecific variation of its vertebral scales, and expands its stratigraphic range into older Uintan 
457 strata. Future studies of stratigraphic distribution among the diverse turtle faunas of the Uinta

458 Fm. may be useful in better understanding local and regional biostratigraphy during the Eocene.

459

460 Conclusions

461

The stratigraphic range of Anosteira pulchra in the Uinta Formation is demonstrated to

462 extend into older Uinta B strata, rather than solely Uinta C. The vast majority of occurrences

463 (78\%) are concentrated in Uinta C localities with mature paleosol development, some with

464 evidence of ponds, where they reach higher abundance than Uinta B localities. Current

465 sedimentological data are insufficient to determine whether this is an ecological preference of $A$.

466 pulchra, a result of changing climate during the late Uinta NALMA, a taphonomic bias

467 associated with less over-bank flooding and greater skeletal accumulation in the uppermost

468 intervals, or some combination of these factors. Considering $A$. pulchra material was present

469 nearly to the bottom of the measured stratigraphic section, future collecting in even older

470 intervals may yield additional insights. Further, given the similarities between the turtle

471 assemblages of the Bridger and Uinta Formations, and the presence of A. pulchra in the

472 intermediate Washakie Fm. (Joyce et al., 2018), additional taxonomic clarification may become

473 possible through additional collecting and study of existing material in institutional repositories.

474 A significant amount of intraspecific variation is apparent in A. pulchra, particularly in

475 the shape of neurals and arrangement of vertebral scales. These are the primary diagnostic

476 characters that distinguish $A$. pulchra from the older $A$. ornata, supporting previous hypotheses

477 toward a single taxon. We suspect that this may indeed be true, however synonymy cannot be

478 confirmed until the description of a larger Bridger Anosteira sample, and an assessment of the

479 stratigraphic range of $A$. ornata are produced.

Peer] reviewing PDF | (2020:06:49966:1:2:NEW 27 Jul 2020) 


\section{Acknowledgements}

482

483

484

485

486

487

488

489

490

491

492

493

494

495

496

497

498

499

500

501

502

The authors wouldlike to thank Dr. Rodney Scheetz of Brigham Young University

Museum of Paleontology, Dr. Carrie Levitt-Bussian of the Natural History Museum of Utah, Dr.

Steve Sroka of the Utah Field House of Natural History State Park Museum, Amy Henrici

(Section of Vertebrate Paleontology) of the Carnegie Museum of Natural History, and the

Department of Vertebrate Paleontology at the Yale Peabody Museum of Natural History, for their assistance in accessing and photographing specimens. Additional thanks to M. Kruback for photographic expertise on BYU specimens. Finally, we thank Drs. Walter Joyce, Ren Hirayama, and Adán Pérez-García for comments and suggestions that greatly improved the quality of the manuscript and figures.

\section{References}

Addison WHF, Appleton JL. 1915. The structure and growth of the incisor teeth of the albino rat. Journal of Morphology 26(1):43-96. https://doi.org/10.1002/jmor.1050260103

Angielczyk, KD, Feldman CR, Miller GR. 2010. Adaptive evolution of plastron shape in emydine turtles. Evolution 65(2):377-394. https://doi.org/10.1111/j.1558$5646.2010 .01118 . x$

Batsch AJGC. 1788. Versuch einer Anleitung, zur Kenntniß und Geschichte der Thiere und Mineralien, für akademische Vorlesungen entworfen, und mit den nöthigsten Abbildungen versehen. Erster Theil. Allgemeine Geschichte der Natur; besondre der Säugthiere, Vögel, Amphibien und Fische. Jena: Akademische Buchhandlung. https://doi.org/10.5962/bhl.title.79854 
503 Bramble DM. 1974. Emydid shell kinesis: biomechanics and evolution. Copeia 1974:707-727.

504

505

506

507

508

509

510

511

512

513

514

515

516

517

518

519

520

521

522

523

524 https://doi.org/10.2307/1442685

Bramble DM, Hutchison JH, Legler JM. 1984. Kinosternid shell kinesis: structure, function and evolution. Copeia 1984(2):456-475. https://doi.org/10.2307/1445203

Broin F de. 1977. Contribution à l'étude des chéloniens: Chéloniens continentaux du Crétacé et du Tertiaire de France. Paris: Éditions du muséum. Mémoires du Muséum National d'histoire naturelle, nouvelle série, Series C, Sciences de la Terre 38:1-366.

Cashion WB. 1967. Geology and fuel resources of the Green River Formation, southeastern Uinta Basin Utah and Colorado. U.S. Geological Survey Professional Paper 548:1-48. https://doi.org/10.3133/pp548

Chamberlain CP, Mix, HT, Mulch A, Hren MT, Kent-Corson ML, Davis SJ, Horton TW, Graham SA. 2012. The Cenozoic climate and topographic evolution of the western North American Cordillera. American Journal of Science 312:213-262. https://doi.org/10.2475/02.2012.5

Clark J. 1932. A new anosteirid from the Uinta Eocene. Annals of the Carnegie Museum 21:161170.

Cope ED. 1868. On some Cretaceous Reptilia. Proceedings of the Academy of Natural Sciences of Philadelphia 1868:233-242.

Dane CH. 1954. Stratigraphic and facies relationships of the Upper part of Green River Formation and Lower part of Uinta Formation in Duchesne, Uintah, and Wasatch Counties, Utah. Bulletin of the American Association of Petroleum Geologists 38:405425. https://doi.org/10.1306/5ceadeea-16bb-11d7-8645000102c1865d 
525 Dane CH. 1955. Stratigraphic and facies relationships of the upper part of the Green River 526 Formation and the lower part of the Uinta Formation in Duchesne, Uintah, and Wasatch

527

528

529

530

531

532

533

534

535

536

537

538

539

540

541

542

543

544

545 Counties, Utah. U.S. Geological Survey Chart OC-52. https://doi.org/10.3133/oc52

Danilov IC, Obraztsova EM, Chen W, Jin J. 2017. The cranial morphology of Anosteira maomingensis (Testudines, Pancarettochelys) and the evolution of Pan-Carettochelyid turtles. Journal of Vertebrate Paleontology 37(4):e1335735. https://doi.org/10.1080/02724634.2017.1335735

Gaffney ES. 1979. Comparative cranial morphology of recent and fossil turtles. Bulletin of the American Museum of Natural History 164(2):1-276.

Gill T. 1889. A remarkable tortoise. In: Annual Report of the Board of Regents of the Smithsonian Institution, for the Year Ending June 30th, 1887, Pt. 1. Washington DC: Government Printing Office, 509-511.

Gilmore CW. 1916. The fossil turtles of the Uinta Formation. Memoirs of the Carnegie Museum 7(2):1-82. https://doi.org/10.5962/bhl.title.44036

Gunnell GF, Murphey PC, Stucky RK, Townsend BKE., Robinson P, Zonneveld J-P, Bartels WS. 2009. Biostratigraphy and biochronology of the latest Wasatchian, Bridgerian, and Uintan North American Land Mammal "Ages". Museum of Northern Arizona Bulletin 65:279-330.

Haglund WD, Reay BS, Swindler DR. 1988. Tooth mark artifacts and survival of bones in animal scavenged human skeletons. Journal of Forensic Sciences 33(4):985-997. https://doi.org/10.1520/jfs12521j 
546 Havlik PE, Joyce WG, Böhme M. 2014. Allaeochelys libyca, a new carettochelyine turtle from 547 the middle Miocene of Libya. Bulletin of the Peabody Museum of Natural History $548 \quad 55: 201-214$. https://doi.org/10.3374/014.055.0207

549 Hay OP. 1906. On two interesting genera of Eocene turtles, Chisternon Leidy and Anosteira 550 Leidy. American Museum of Natural History Bulletin 22:155-160.

551 Hay OP. 1908. The Fossil Turtles of North America. Carnegie Inst. Washington Publications 552 75:1-568. https://doi.org/10.5962/bhl.title. 12500

553

554

555

556

557

558

559

560

561

562

563

564

565

566

Hummel K. 1929. Die fossilen Weichschildkroten (Trionychia). Eine morphologischesystematische und stammesgeschichtliche. Studie. Geol. Palaeontol. 16:359-487.

Hutchison JH. 1996. Testudines. In: Prothero DR, Emery RJ, eds. The Terrestrial EoceneOligocene Transition in North America. Cambridge: Cambridge University Press, 337353. https://doi.org/10.1017/CBO9780511665431

Hutchison JH. 1998. Turtles across the Paleocene/Eocene Epoch Boundary in West-Central North America, p. 401-408. In: Aubry M-P, Lucas SG, Berggren WA, eds. Late Paleocene-Early Eocene climatic and biotic events in the marine and terrestrial records. Princeton: Princeton University Press.

Hutchison JH, Frye FL. 2001. Evidence of pathology in early Cenozoic turtles. PaleoBios 21(3):12-19.

Hutchison JH, Holroyd PA, and Ciochon RL. 2004. A preliminary report on southeast Asia's oldest Cenozoic turtle fauna from the late middle Eocene Pondaung Formation, Myanmar. Asiatic Herpetological Research 10:38-52.

Peer) reviewing PDF | (2020:06:49966:1:2:NEW 27 Jul 2020) 
567 Joyce WG. 2014. A review of the fossil record of turtles of the clade Pan-Carettochelys. Bulletin 568 of the Peabody Museum of Natural History 55:3-33.

569 https://doi.org/10.3374/014.055.0102

570 Joyce WG, Parham JF, and Gauthier JA. 2004. Developing a protocol for the conversion of rank571 based taxon names to phylogenetically define clade names, as exemplified by turtles.

572 Journal of Paleontology 78(5):989-1013. https://doi.org/10.1666/0022-

573 3360(2004)078<0989:dapftc $>2.0$. co;2

574 Joyce WG, Micklich N, Schaal SFK, Scheyer TM. 2012. Caught in the act: the first record of $575 \quad$ copulating fossil vertebrates. Biology Letters 8:846-848.

576 https://doi.org/10.1098/rsbl.2012.0361

577 Joyce WG, Lyson TR. 2015. A review of the fossil record of turtles of the clade Baenidae. 578 Bulletin of the Peabody Museum of Natural History 56(2):147-183.

579 https://doi.org/10.3374/014.056.0203

580

Joyce WG, Volpato VS, Rollot Y. 2018. The skull of the carettochelyid turtle Anosteira pluchra 581

582 from the Eocene (Uintan) of Wyoming and the carotid canal system of carettochelyid turtles. Fossil Record 21:301-310. https://doi.org/10.5194/fr-21-301-2018

583

Leidy J. 1871. [Remarks on some extinct turtles from Wyoming Territory]. Proceedings of the 585 Academy of Natural Sciences of Philadelphia 1871:102-103.

Meylan PA, Gaffney ES. 1989. The skeletal morphology of the Cretaceous cryptodiran turtle, 586 Adocus, and the relationships of the Trionychoidea. American Museum Novitates 2941:1-

587 60.

588 Murphey PC, Townsend KEB, Friscia AR, Evanoff E. 2011. Paleontology and stratigraphy of 589 middle Eocene rock units in the Bridger and Uinta Basins, Wyoming and Utah. The 

https://doi.org/10.1130/2011.0021(06)

592 Murphey PC, Townsend KEB, Friscia AR, Westgate J, Evanoff E, Gunnell GF. 2017.

593 Paleontology and stratigraphy of Middle Eocene Rock Units in the Southern Green River 594 and Uinta Basins, Wyoming and Utah. Geology of the Intermountain West 4:1-53. https://doi.org/10.31711/giw.v4i0.11

Osborn HF. 1895. Fossil mammals of the Uinta Basin-expedition of 1894. Bulletin of the 597 American Museum of Natural History 7(2):71-105.

598

599

600

601

602

603

604

605

606

607

608

609

610
Osborn HF. 1929. The Titanotheres of ancient Wyoming, Dakota, and Nebraska. U.S. Geological Survey Monograph 55(1):1-701. https://doi.org/10.3133/m55

Prothero DR. 1996. Magnetic stratigraphy and biostratigraphy of the middle Eocene Uinta Formation, Uinta Basin, Utah. In: Prothero DR, Emry RJ, eds. The Terrestrial EoceneOligocene Transition in North America. Cambridge: Cambridge University Press, 3-24. https://doi.org/10.1017/cbo9780511665431.002

Pobiner B. 2008. Paleoecological information in predator tooth marks. Journal of Taphonomy $6(3-4): 373-397$.

Rasband WS. 1997-2016. ImageJ. Bethesda: U. S. National Institutes of Health.

Rasmussen DT, Conroy GC, Friscia AR, Townsend KE, Kinkel MD. 1999. Mammals of the middle Eocene Uinta Formation. In: Gillette DD, ed. Vertebrate Paleontology in Utah: Utah Geological Survey Miscellaneous Publication 99-1. Salt Lake City: Utah Geological Survey, 401-420. 
611 Ray RG, Kent BH, Dane CH. 1956. Stratigraphy and photogeology of the southwestern part of 612 the Uinta Basin, Duchesne and Uintah Counties, Utah. U.S. Geological Survey Oil and Gas Investigations Map OM-171.

614 Riggs ES. 1912. New or little known titanotheres from the lower Uintah formations — with notes 615 on the stratigraphy and distribution of fossils. Field Museum of Natural History

616 Publication 159(2):17-41. https://doi.org/10.5962/bhl.title.3381

617 Ryder RT, Fouch TD, Elison JH. 1976. Early Tertiary sedimentation in the western Uinta Basin, 618 Utah. GSA Bulletin 87:469-512. https://doi.org/10.1130/0016-

619 7606(1976)87<496:etsitw>2.0.co;2

620

621

622

623

624

625

626

627

628 629

630

631

632

Smith HF, Hutchison JH, Townsend KEB, Adrian B, Jager D. 2017. Morphological variation, phylogenetic relationships, and geographic distribution of the Baenidae (Testudines), based on new specimens from the Uinta Formation (Uinta Basin), Utah (USA). PLoS ONE. https://doi.org/10.1371/journal.pone.0180574: 1-40.

Smith HF, Jager D, Hutchison JH, Adrian B, Townsend KEB. 2020. Epiplastral and geographic variation in Echmatemys, a geoemydid turtle from the Eocene of North America: A multi-tiered analysis of epiplastral shape complexity. Paleobios 37.ucmp_paleobios_46852: 1-14.

Sprinkel DA. 2007. Interim geologic map of the Vernal 30' x 60' Quadrangle, Uintah and Duchesne Counties, Utah and Moffat and Rio Blanco Counties, Colorado. Utah Geological Survey Open-File Report 506DM: Plate 1.

Sprinkel DA. 2018. Interim geologic map of the Duchesne 30' x 60' Quadrangle, Duchesne and Wasatch Counties, Utah. Utah Geological Survey Open-File Report OFR-689: Plate 1. 
633 Stidham TA, Townsend KEB, Holroyd PA. 2020. Evidence for wide dispersal in a stem

634

635

636

637

638

639

640

641

642

643

644

645

646

647

648

649

650

651

652

653

654

655

galliform clade from a new small-sized middle Eocene pangalliform (Aves:

Paraortygidae) from the Uinta Basin of Utah (USA). Diversity 12(90):1-13.

https://doi.org/10.3390/d12030090

Townsend KEB, Friscia AR, Rasmussen DT. 2006. Stratigraphic distribution of upper middle Eocene fossil vertebrate localities in the Eastern Uinta Basin, Utah, with comments on Uintan biostratigraphy. The Mountain Geologist 43(2):115-134.

Townsend KEB, Rasmussen DT, Murphey PC, Evanoff E. 2010. Middle Eocene habitat shifts in the North American western interior: A case study. Palaeogeography, Palaeoclimatology, Palaeoecology 297:144-158. https://doi.org/10.1016/j.palaeo.2010.07.024

Weijs WA. 1975. Mandibular movements of the albino rat during feeding. Journal of Morphology 145(1):107-124. https://doi.org/10.1002/jmor.1051450107

Westgate J, Townsend KEB, Cope D, Gartner C. 2013. Progress report on the first Uinta C micro-mammal fauna from the Uinta Basin and its comparison with the Casa Blanca mammal community from Laredo, Texas. Geological Society of America Abstracts with Programs. Denver: Geological Society of America:325.

Wood HE, Chaney RW, Clark J, Colbert EH, Jepsen GL, Reeside JB, Stock C. 1941. Nomenclature and correlation of the North American continental Tertiary. Geological Society of America Bulletin 52:1-48. https://doi.org/10.1130/gsab-52-1

\section{Additional Information}

\section{Funding}

Peer) reviewing PDF | (2020:06:49966:1:2:NEW 27 Jul 2020) 
656 Funding for this research was provided by Midwestern University faculty intramural funds (to

657 K.E. Beth Townsend).

658 Competing Interests

659 The authors declare there are no competing interests.

660 Author Contributions

661 - Brent Adrian analyzed the data, wrote the paper, prepared figures and/or tables, reviewed

662 drafts of the paper.

663 - Patricia A. Holroyd reviewed drafts of the paper and prepared Figure 1.

664 - J. Howard Hutchison reviewed drafts of the paper.

665 - K.E. Beth Townsend reviewed drafts of the paper and prepared Table 1.

666

667 Captions

668 Figure 1. Index map of Utah and collection sites of Anosteira pulchra in the current study.

669 Figure 2. Stratigraphic distribution of $A$. pulchra in the upper Uinta Fm. (A) Stratigraphic

670 sections indicating marker unit correlation of the six sections of the Uinta Fm. (Townsend,

671 Friscia \& Rasmussen, 2006). (B) Minimum number of $A$. pulchra individuals. Green rectangle

672 corresponds with meter level range for WU-34 (226-248 m). (C) Correlation of the measured

673 stratigraphic section of Townsend, Friscia \& Rasmussen (2006) relative to the Global Magnetic

674 Polarity Time scale, using magnetostratigraphic section of Townsend et al. (2010) and Prothero

675 (1996).

676 Figure 3. Carapace material of Anosteira pulchra from the Uinta Fm. (A-B) Dorsal (left) and

677 ventral (right) views of UMNH.VP.27632, an articulated nuchal and left first peripheral. (C)

678 Right lateral view of UMNH.VP.31059, an articulated neural 3 and 4. (D) Right lateral view of 
679 UMNH.VP.27146, a partial articulated carapace. (E-F) Dorsal (left) and ventral (right) views of 680 a partial carapace, UMNH.VP.27146. (G-I) Dorsal (left), ventral (center), and lateral (right) 681 views of UMNH.VP.30590, neurals 6 and 7. (J-L) Dorsal (left), ventral (center), and lateral 682 (right) views of pygal and suprapygal from the same specimen. (M-N) Dorsal (left) and ventral 683 (right) views of UMNH.VP.19951, a right costal 1. (O-Q) Dorsal (left), ventral (center), and 684 posterior (right) views of UMNH.VP.31058, a right peripheral 2. (R-T) Dorsal (left), ventral 685 (center), and anterior (right) views of UMNH.VP.27077, a left peripheral 3. (U-X) Dorsal (left), 686 ventral (left center), medial (right center), and posterior (right) views of UMNH.VP.27077, a left 687 peripheral 6. (Y-AA) Dorsal (left), ventral (center), and anterior (right) of UMNH.VP.30590, a 688 right peripheral 8. Dotted black lines indicate edges of missing bone, vertical blue lines indicate 689 orientation of the midline, and purple lines indicate sulci. All parts of figure to same scale. 690 Figure 4. Plastral material of Anosteira pulchra from the Uinta Fm. (A-B) Ventral (left), and 691 dorsal (right) views of UMNH.VP.19551, a partial left plastron. (C-D) Ventral (left) and dorsal 692 (right) views of a UMNH.VP.27452, a nearly complete left hypoplastron. (E-G) Ventral (left), 693 medial (center), and dorsal (right) views of UMNH.VP.26554, a partial left hypoplastron. (H-I) 694 Ventral (left), and dorsal (right) views of UMNH.VP.26917, a partial right hypoplastron with 695 probably rodent gnaw marks circled in red. (J-M) Ventral (left), dorsal (left center), medial (right 696 center), and lateral (right) views of UMNH.VP.20525, a nearly complete right xiphiplastron. 697 UMNH.VP specimen numbers are in rectangles. All parts of figure to same scale. Dotted black 698 lines indicate edges of missing bone and vertical blue lines indicate orientation of the midline. 699 Figure 5. Magnified ventral surface of hypoplastral fragment UMNH.VP.26917, showing traces 700 of rodent incisors (indicated by arrows) near the hypo-xiphiplastron suture. Scale shows $1 \mathrm{~mm}$ 701 increments and black arrows indicate orientation. 
702 Figure 6. Associated carapace and plastron of Anosteira pulchra, specimen UMNH.VP.31072.

703 (A) Vertebral series and suprapygal in dorsal view. (B) Plastron and peripheral ring in dorsal

704 view. (C) Vertebral series and suprapygal in ventral view. (D) Plastron and peripheral ring in

705 ventral view. All parts of figure to same scale. Vertical blue lines indicate orientation of the 706 midline.

707 Figure 7. Scale pattern variation within Anosteira pulchra. (A) Dorsal carapace of CM 11808, 708 type specimen of $A$. pulchra. (B) Detail of carapacial scale pattern of CM 11808 as previously

709 published (Clark, 1932), with yellow star indicating unmarked region of shell. (C) Dorsal

710 carapace of YPM VPPU 16318, mentioned in Joyce (2014). (D) Detail of carapacial scale pattern

711 of YPM VPPU 16318. (E) Dorsal carapace of YPM VPPU 16317, mentioned in Havlik, Joyce \&

712 Böhme (2014) and Joyce (2014). (F) Detail of carapacial scale pattern of YPM VPPU 16317. (G)

713 Partial carapace with scale pattern of UMNH.VP.27146. (H) Scale pattern of neural spike of

714 larger individual in dorsolateral view of UMNH.VP.27453. (I) Scale pattern of third neural of

715 smaller individual in dorsolateral view of UMNH.VP.27453. (J) Scale pattern of partial carapace

716 of UMNH.VP.31072 in dorsal view. Red lines indicate sulci and black lines indicate sutures.

717 Photos of YPM specimens courtesy of Yale Peabody Museum of Natural History

718 (https://collections.peabody.yale.edu/search/).

719 Table 1. Uinta Fm. Anosteira pulchra specimens by stratigraphic meter level. * indicates a BYU 720 locality that is not assigned a meter level.

721 Table 2. Anosteira pulchra records from the Uinta Fm. outside of the measured stratigraphic 722 section of Townsend, Friscia \& Rasmussen (2006). 


\section{Table 1 (on next page)}

Uinta Fm. Anosteira specimens by stratigraphic meter level.

Uinta Fm. Anosteira specimens by stratigraphic meter level. $*$ indicates a BYU locality that is not assigned a meter level. 
1 Table 1. Uinta Fm. Anosteira specimens by stratigraphic meter level. * indicates a BYU locality 2 that is not assigned a meter level.

\begin{tabular}{|c|c|c|c|}
\hline Specimen & $\begin{array}{l}\text { MWU } \\
\text { locality }\end{array}$ & $\begin{array}{l}\text { Meter } \\
\text { Level }\end{array}$ & Element \\
\hline UMNH.VP.27635 & WU-123 & 366 & Shell fragments \\
\hline UMNH.VP.27634 & WU-49 & 364 & Neurals; many shell fragments \\
\hline UMNH.VP.27212 & WU-49 & 364 & Shell fragments \\
\hline UMNH.VP.27077 & WU-50 & 361 & Left peripherals 3,6 \\
\hline UMNH.VP.27202 & WU-50 & 361 & $\begin{array}{l}\text { Left peripheral 7; right hypoplastron fragment; } \\
\text { articulated right nuchal/peripheral } 1\end{array}$ \\
\hline UMNH.VP.27146 & WU-50 & 361 & $\begin{array}{l}\text { Partial left hypoplastron; right peripherals } 1-2 \text {, } \\
\text { possible } 4,10 \text {; neurals } 2-4,6 \text {; costals } 3-5\end{array}$ \\
\hline UFH 2002.19.2 & WU-185 & 334 & Partial carapace including neural \\
\hline UFH 2002.19.3 & WU-185 & 334 & Shell fragments \\
\hline UMNH.VP.27299 & WU-223 & 332 & Pygal \\
\hline UMNH.VP.27307 & WU-223 & 332 & $\begin{array}{l}\text { Right peripheral } 6,8,10 \text {; pygal; possible left } \\
\text { hyoplastron frag; partial right xiphiplastron; } 1 \\
\text { possible right hypoplastral fragment }\end{array}$ \\
\hline UMNH.VP.26539 & WU-223 & 332 & Left peripherals 5-6 \\
\hline UMNH.VP.26917 & $\begin{array}{l}\text { Above } \\
\text { WU-216 }\end{array}$ & 286 & Right hypoplastron fragment \\
\hline UMNH.VP.26919 & $\begin{array}{l}\text { Above } \\
\text { WU-216 }\end{array}$ & 286 & Superpygal \\
\hline
\end{tabular}




\begin{tabular}{|c|c|c|c|}
\hline UMNH.VP.26504 & $\begin{array}{l}\text { Above } \\
\text { WU-216 }\end{array}$ & 286 & Partial pygal; partial peripheral \\
\hline UMNH.VP.26920 & $\begin{array}{l}\text { Above } \\
\text { WU-216 }\end{array}$ & 286 & Plastron fragment \\
\hline UMNH.VP.26511 & $\begin{array}{l}\text { Above } \\
\text { WU-216 }\end{array}$ & 286 & Carapace fragments \\
\hline UMNH.VP.18945 & WU-45 & 285 & Plastron and carapace fragments \\
\hline UMNH.VP.20505 & WU-216 & 284 & $\begin{array}{l}\text { Right peripherals 1, 6-7; partial neural; costal } \\
\text { fragments }\end{array}$ \\
\hline UMNH.VP.20506 & WU-216 & 284 & Partial hypoplastron \\
\hline UMNH.VP.20518 & WU-216 & 284 & Carapace fragments \\
\hline UMNH.VP.20498 & WU-216 & 284 & Pygal; costal fragments; posterior hypoplastron \\
\hline UMNH.VP.20479 & WU-216 & 284 & Carapace fragments \\
\hline UMNH.VP.20496 & WU-216 & 284 & Partial nuchal; partial costal; partial hyoplastron \\
\hline UMNH.VP.20525 & WU-216 & 284 & $\begin{array}{l}\text { Partial costals; left peripherals 1-6, right } \\
\text { peripherals 4-6; pygal; right xiphiplastron }\end{array}$ \\
\hline UMNH.VP.20523 & WU-216 & 284 & Right peripheral 6 \\
\hline UMNH.VP.20522 & WU-216 & 284 & Right peripheral 6 \\
\hline UMNH.VP.20532 & WU-216 & 284 & Carapace fragments \\
\hline UMNH.VP.20533 & WU-216 & 284 & Carapace and plastron fragments \\
\hline UMNH.VP.20535 & WU-216 & 284 & Carapace and plastron fragments \\
\hline UMNH.VP.20536 & WU-216 & 284 & Carapace and plastron fragments \\
\hline UMNH.VP.20537 & WU-216 & 284 & Carapace and plastron fragments \\
\hline
\end{tabular}




\begin{tabular}{|l|l|l|l|}
\hline UMNH.VP.20538 & WU-216 & 284 & Carapace and plastron fragments \\
\hline UMNH.VP.20539 & WU-216 & 284 & Carapace and plastron fragments \\
\hline UMNH.VP.20540 & WU-216 & 284 & Carapace and plastron fragments \\
\hline UMNH.VP.20541 & WU-216 & 284 & Carapace and plastron fragments \\
\hline UMNH.VP.20542 & WU-216 & 284 & Carapace and plastron fragments \\
\hline UMNH.VP.20543 & WU-216 & 284 & Carapace and plastron fragments \\
\hline UMNH.VP.20551 & WU-216 & 284 & Carapace and plastron fragments \\
\hline UMNH.VP.20552 & WU-216 & 284 & Carapace and plastron fragments \\
\hline UMNH.VP.20553 & WU-216 & 284 & Carapace and plastron fragments \\
\hline UMNH.VP.17724 & WU-121 & 282 & Carapace fragments \\
\hline UMNH.VP.30592 & WU-134 & $226-248$ & Partial peripherals; small fragments \\
\hline UMNH.VP.30593 & WU-134 & $226-248$ & Small fragments \\
\hline UMNH.VP.30594 & WU-134 & $226-248$ & Partial peripherals; many small fragments \\
\hline UMNH.VP.30595 & WU-134 & $226-248$ & Left peripherals 5, 6, 8; plastron fragment \\
\hline UMNH.VP.27424 & WU-134 & $226-248$ & Pygal; partial peripherals; shell fragments \\
\hline UMNH.VP.20582 & WU-134 & $226-248$ & Carapace fragments \\
\hline UMNH.VP.20583 & WU-134 & $226-248$ & Carapace fragments \\
\hline UMNH.VP.20584 & WU-134 & $226-248$ & Carapace fragments \\
\hline UMNH.VP.30596 & WU-134 & $226-248$ & Costal fragments; peripherals \\
\hline UMNH.VP.30597 & WU-134 & $226-248$ & Neurals 2-3; plastron fragments \\
\hline UMNH.VP.30598 & WU-134 & & Pygal; peripheral fragments; carapace fragments; \\
\hline wM-134 & $226-248$ & Neural; partial peripheral; fragments \\
\hline & & $226-248$ & plastron fragments \\
\hline
\end{tabular}




\begin{tabular}{|c|c|c|c|}
\hline UMNH.VP.30600 & WU-134 & $226-248$ & $\begin{array}{l}\text { Neural } 5 \text { or 6; right peripherals 5-6; left } \\
\text { peripherals 3-6; left possible hyoplastron } \\
\text { fragment; anterior peripherals; carapace } \\
\text { fragments; plastron fragments }\end{array}$ \\
\hline UMNH.VP.30602 & WU-134 & $226-248$ & $\begin{array}{l}\text { Left peripheral 5; left possible hypoplastron } \\
\text { fragment; indet. plastron fragment. }\end{array}$ \\
\hline UMNH.VP.30603 & WU-134 & $226-248$ & Costals; neurals \\
\hline UMNH.VP.30604 & WU-134 & $226-248$ & $\begin{array}{l}\text { Articulated partial anterior carapace including } \\
\text { nuchal }\end{array}$ \\
\hline UMNH.VP.30605 & WU-134 & $226-248$ & $\begin{array}{l}\text { Neurals 2-4; anterior peripheral; partial } \\
\text { peripheral; many tiny fragments }\end{array}$ \\
\hline UMNH.VP.27450 & WU-134 & $226-248$ & Peripheral; shell fragments \\
\hline UMNH.VP.27452 & WU-134 & $226-248$ & Pygal; left hypoplastron \\
\hline UMNH.VP.30586 & WU-134 & $226-248$ & Many small fragments \\
\hline UMNH.VP.30587 & WU-134 & $226-248$ & Many costal fragments \\
\hline UMNH.VP.30588 & WU-134 & $226-248$ & Partial left hypoplastron \\
\hline UMNH.VP.30589 & WU-134 & $226-248$ & Partial peripherals; small fragments \\
\hline UMNH.VP.30590 & WU-134 & $226-248$ & Right peripheral 8, neurals 6-7, pygal, suprapygal \\
\hline UMNH.VP.30591 & WU-134 & $226-248$ & Left and right peripheral 1 \\
\hline UMNH.VP.30910 & WU-134 & $226-248$ & Neurals 2-3 \\
\hline UMNH.VP.27226 & WU-134 & $226-248$ & Small fragments (mostly plastron) \\
\hline UMNH.VP.27453 & WU-134 & $226-248$ & $\begin{array}{l}\text { Partial pygal; partial nuchal; partial peripherals; } \\
\text { small fragments }\end{array}$ \\
\hline
\end{tabular}




\begin{tabular}{|l|l|l|l|}
\hline UMNH.VP.27630 & WU-134 & $226-248$ & Plastral fragments \\
\hline UMNH.VP.27454 & WU-134 & $226-248$ & Right xiphiplastron fragment \\
\hline UMNH.VP.27632 & WU-134 & $226-248$ & Nuchal; left peripheral 1 \\
\hline UMNH.VP.26515 & WU-26 & 237 & Many small plastron fragments \\
\hline UMNH.VP.26554 & WU-26 & & Neurals 1-3; partial left hypoplastron; probable \\
& & 237 & femora; partial peripherals; many tiny fragments \\
\hline UMNH.VP.31070 & WU-26 & 237 & Partial peripherals; many fragments \\
\hline UMNH.VP.31058 & WU-26 & 237 & Peripheral 2; partial costals; small fragments \\
\hline UMNH.VP.31059 & WU-26 & 237 & Neurals 3-4; small fragments \\
\hline UMNH.VP.31060 & WU-26 & 237 & Partial peripherals; small fragments \\
\hline UMNH.VP.26556 & WU-26 & 237 & Bridge peripherals \\
\hline UMNH.VP.19951 & WU-12 & 141 & Right costal 1 \\
\hline UMNH.VP.27281 & WU-1 & & 3 possible individuals; Partial peripherals; shell \\
fragments; 3 pygals; right peripheral 1
\end{tabular}




\begin{tabular}{|l|l|l|l|}
\hline UMNH.VP.20661 & WU-32 & $>95$ & Right peripherals 6, 7 \\
\hline UMNH.VP.27306 & WU-23 & & Left and right peripheral 5; posterior peripheral \\
& & $\sim 83$ & fragments \\
\hline UMNH.VP.31072 & WU-8 & $57-60$ & Associated partial carapace and plastron \\
\hline UMNH.VP.31073 & WU-8 & $57-60$ & Pygal \\
\hline UMNH.VP.27243 & WU-18 & & 2 individuals; partial peripherals; plastron \\
& & & fragments; pygals; left hypoplastron; \\
& & 25 & indeterminate shell fragments \\
\hline
\end{tabular}

3 


\section{Table 2 (on next page)}

Anosteira pulchra records from the Uinta Fm. outside of the measured stratigraphic section of Townsend, Friscia \& Rasmussen (2006).

Anosteira pulchra records from the Uinta Fm. outside of the measured stratigraphic section of Townsend, Friscia \& Rasmussen (2006). 
1 Table 2. Anosteira pulchra records from the Uinta Fm., outside of the measured stratigraphic

2 section of Townsend, Friscia \& Rasmussen (2006).

\begin{tabular}{|c|c|c|}
\hline Specimen & Locality & Element \\
\hline UCMP 218731 & V98069 & Shell fragments \\
\hline UCMP 223356 & V98069 & $\begin{array}{l}\text { Hyo- or hypoplastral } \\
\text { fragment }\end{array}$ \\
\hline UCMP 223357 & V98069 & $\begin{array}{l}\text { Hyo- or hypoplastral } \\
\text { fragment }\end{array}$ \\
\hline UCMP 223358 & V98069 & Bridge peripheral \\
\hline UCMP 223359 & V98069 & Peripheral \\
\hline UCMP 223360 & V98069 & Peripheral \\
\hline UCMP 223361 & V98069 & Peripheral \\
\hline UCMP 235587 & V98069 & Bridge peripheral \\
\hline UCMP 235588 & V87136 & $\begin{array}{l}\text { Left hyoplastron and } \\
\text { shell fragments }\end{array}$ \\
\hline UCMP 223098 & V71057 & Peripheral 2 \\
\hline UCMP 223099 & V71057 & Peripheral 8 \\
\hline UCMP 218732 & V71058 & Shell fragments \\
\hline UCMP 223355 & V71058 & Shell fragments \\
\hline
\end{tabular}

3 
Figure 1

Index map of Utah and collection sites of Anosteira pulchra in the current study.

Index map of Utah and collection sites of Anosteira pulchra in the current study.

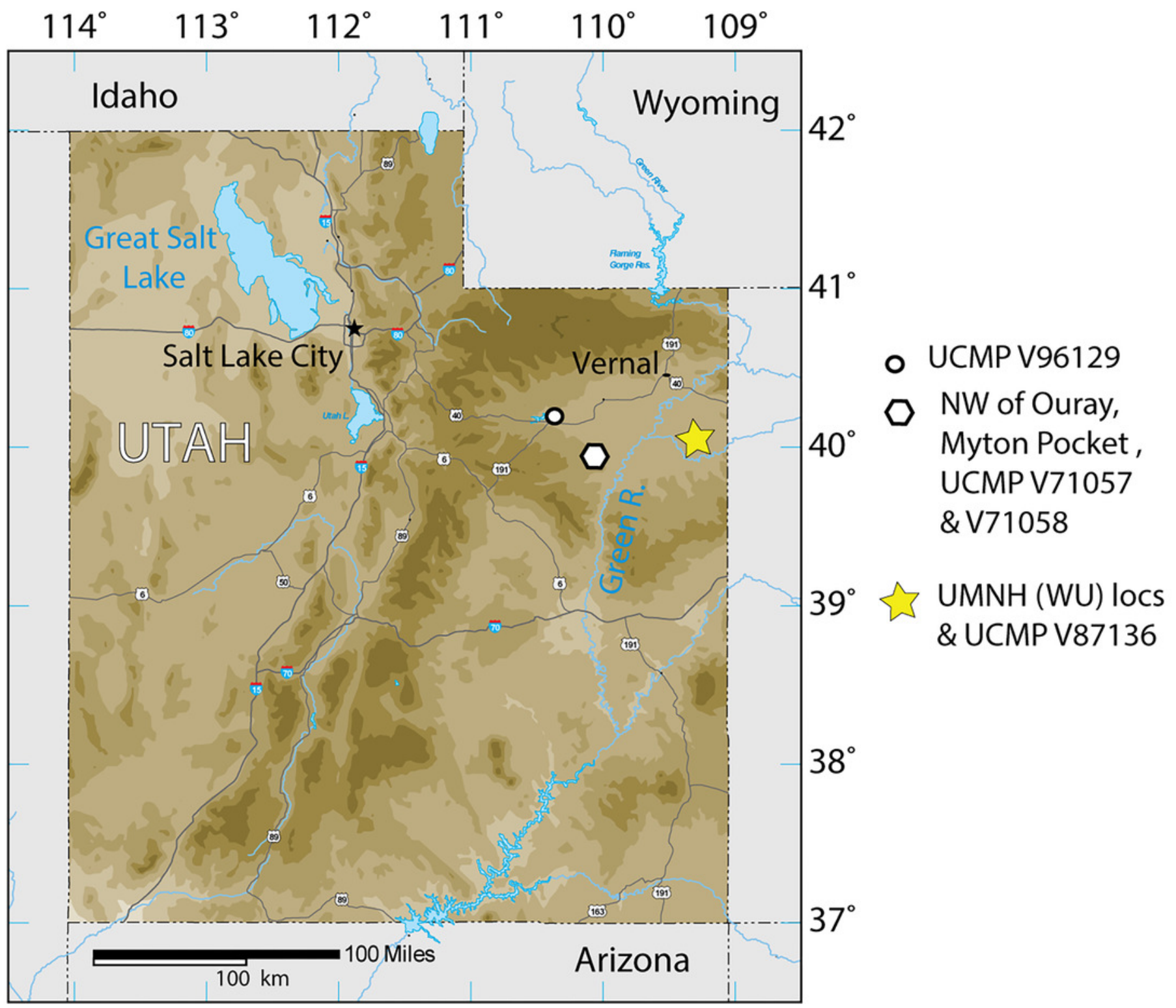




\section{Figure 2}

Stratigraphic distribution of $A$. pulchra in the upper Uinta Fm.

(A) Stratigraphic sections indicating marker unit correlation of the six sections of the Uinta Fm. (Townsend, Friscia \& Rasmussen, 2006). (B) Minimum number of $A$. pulchra individuals. Green rectangle corresponds with meter level range for WU-34 (226-248 m). (C) Correlation of the measured stratigraphic section of Townsend, Friscia \& Rasmussen (2006) relative to the Global Magnetic Polarity Time scale, using magnetostratigraphic section of Townsend et al. (2010) and Prothero (1996). 


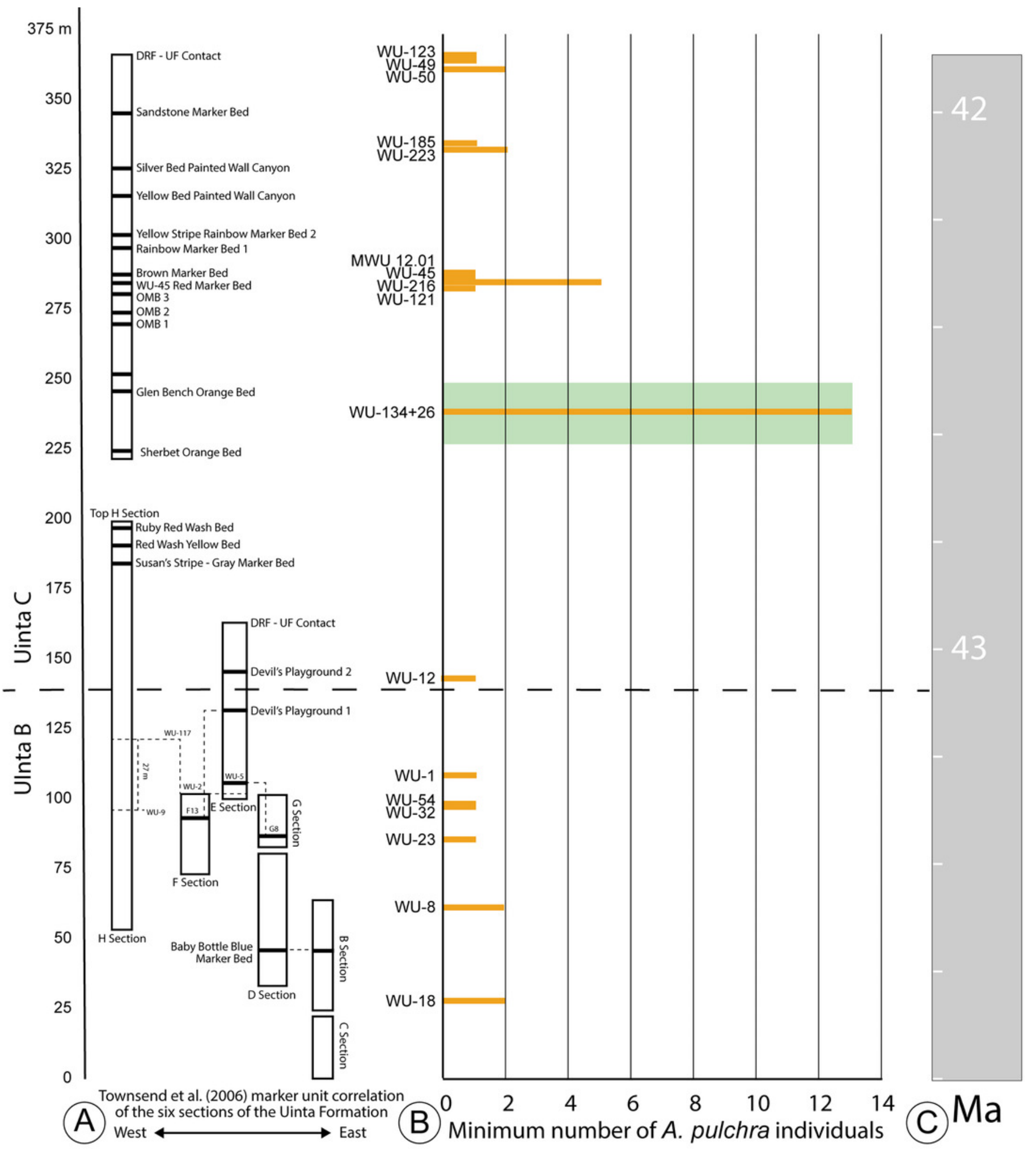




\section{Figure 3}

Carapace material of Anosteira pulchra from the Uinta Fm.

(A-B) Dorsal (left) and ventral (right) views of UMNH.VP.27632, an articulated nuchal and left first peripheral. (C) Right lateral view of UMNH.VP.31059, an articulated neural 3 and 4. (D) Right lateral view of UMNH.VP.27146, a partial articulated carapace. (E-F) Dorsal (left) and ventral (right) views of a partial carapace, UMNH.VP.27146. (G-I) Dorsal (left), ventral (center), and lateral (right) views of UMNH.VP.30590, neurals 6 and 7. (J-L) Dorsal (left), ventral (center), and lateral (right) views of pygal and suprapygal from the same specimen. (M-N) Dorsal (left) and ventral (right) views of UMNH.VP.19951, a right costal 1. (O-Q) Dorsal (left), ventral (center), and posterior (right) views of UMNH.VP.31058, a right peripheral 2. (RT) Dorsal (left), ventral (center), and anterior (right) views of UMNH.VP.27077, a left peripheral 3. (U-X) Dorsal (left), ventral (left center), medial (right center), and posterior (right) views of UMNH.VP.27077, a left peripheral 6. (Y-AA) Dorsal (left), ventral (center), and anterior (right) of UMNH.VP.30590, a right peripheral 8. Dotted black lines indicate edges of missing bone, vertical blue lines indicate orientation of the midline, and purple lines indicate sulci. All parts of figure to same scale. 


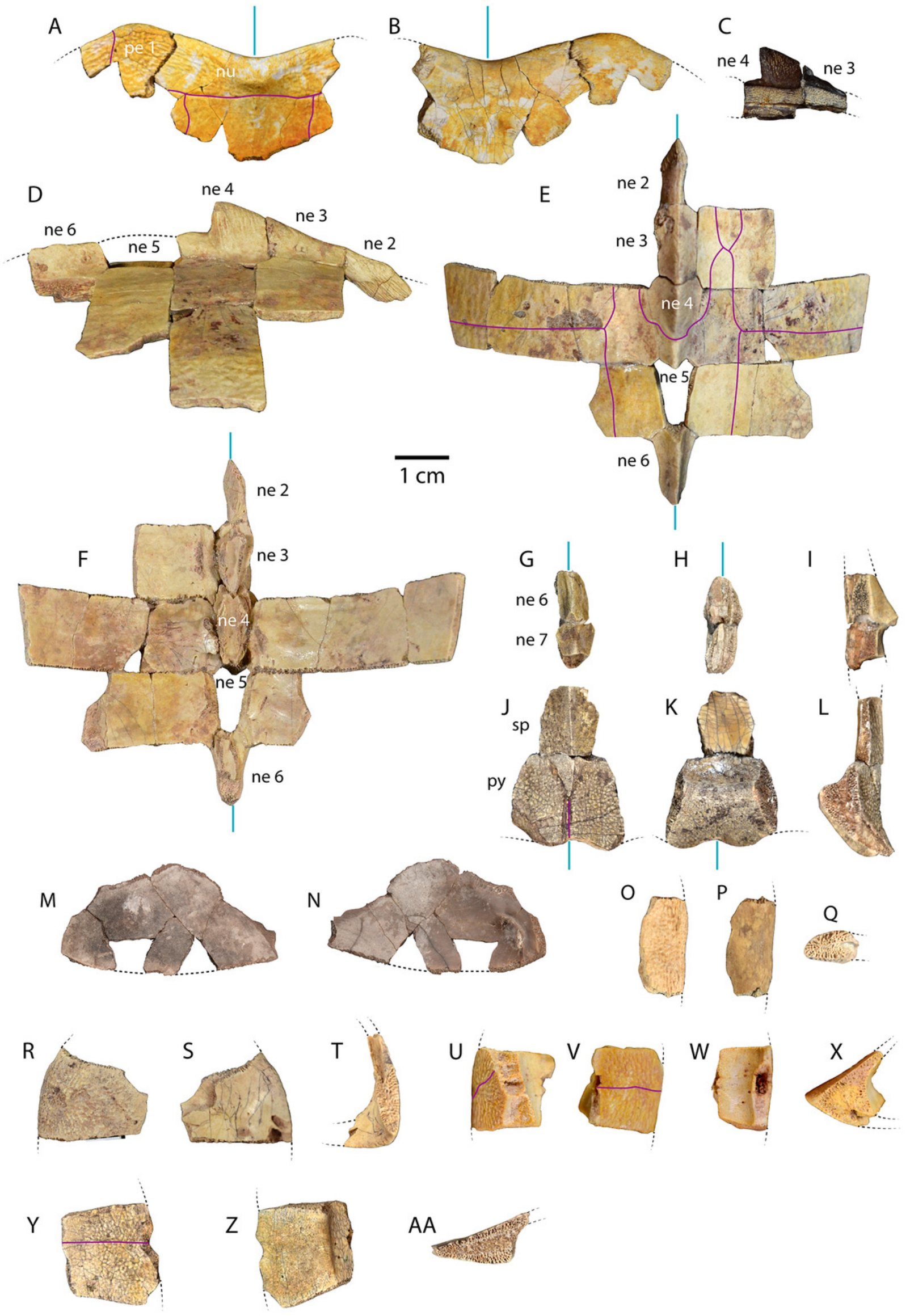




\section{Figure 4}

Plastral material of Anosteira pulchra from the Uinta Fm.

(A-B) Ventral (left), and dorsal (right) views of UMNH.VP.19551, a partial left plastron. (C-D) Ventral (left) and dorsal (right) views of a UMNH.VP.27452, a nearly complete left hypoplastron. (E-G) Ventral (left), medial (center), and dorsal (right) views of UMNH.VP.26554, a partial left hypoplastron. (H-I) Ventral (left), and dorsal (right) views of UMNH.VP.26917, a partial right hypoplastron with probably rodent gnaw marks circled in red. (J-M) Ventral (left), dorsal (left center), medial (right center), and lateral (right) views of UMNH.VP.20525, a nearly complete right xiphiplastron. UMNH.VP specimen numbers are in rectangles. All parts of figure to same scale. Dotted black lines indicate edges of missing bone and vertical blue lines indicate orientation of the midline. 

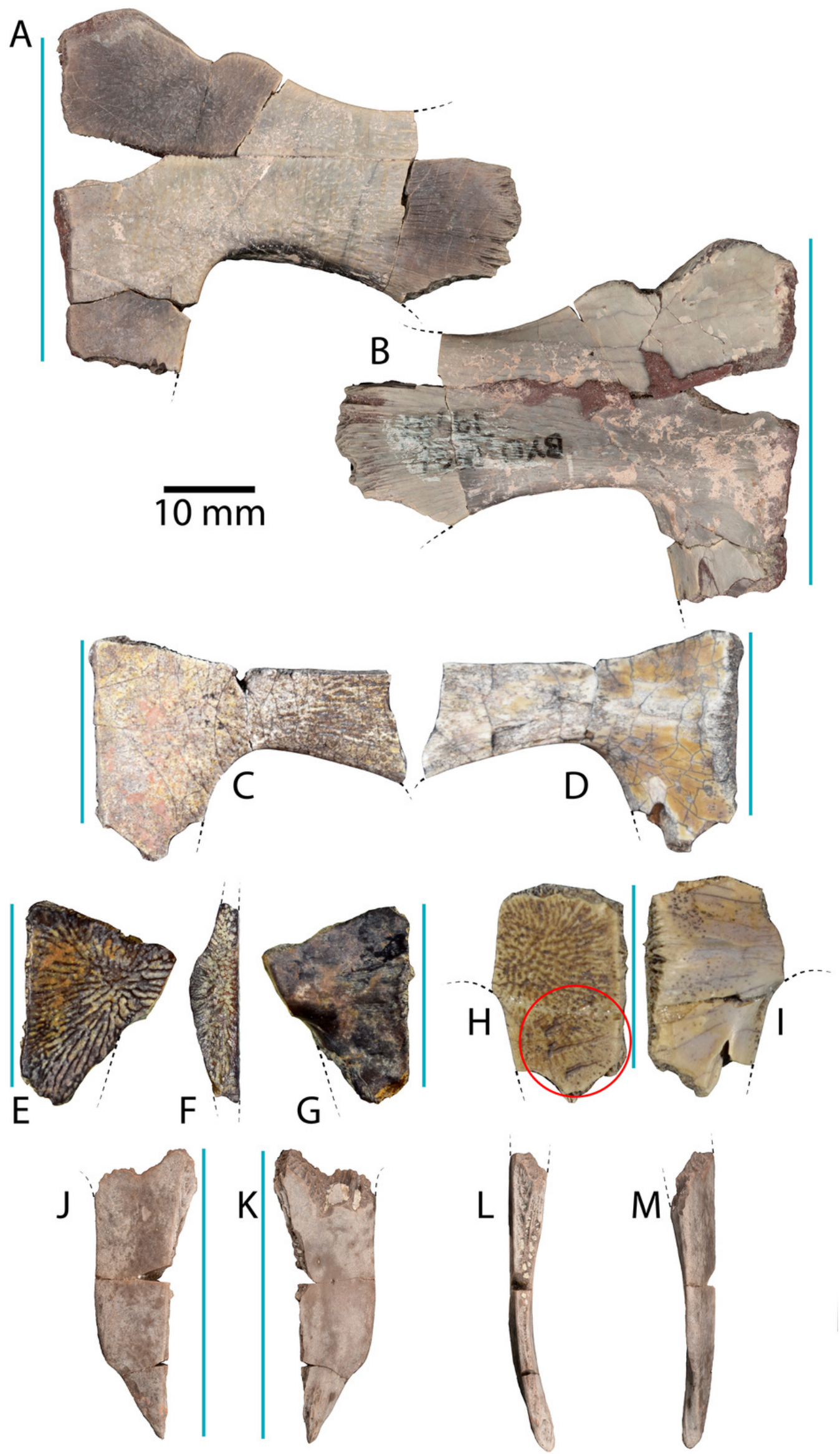
Figure 5

Magnified ventral surface of hypoplastral fragment UMNH.VP.26917, showing traces of rodent incisors (indicated by arrows) near the hypo-xiphiplastron suture.

Scale shows $1 \mathrm{~mm}$ increments and black arrows indicate orientation. 


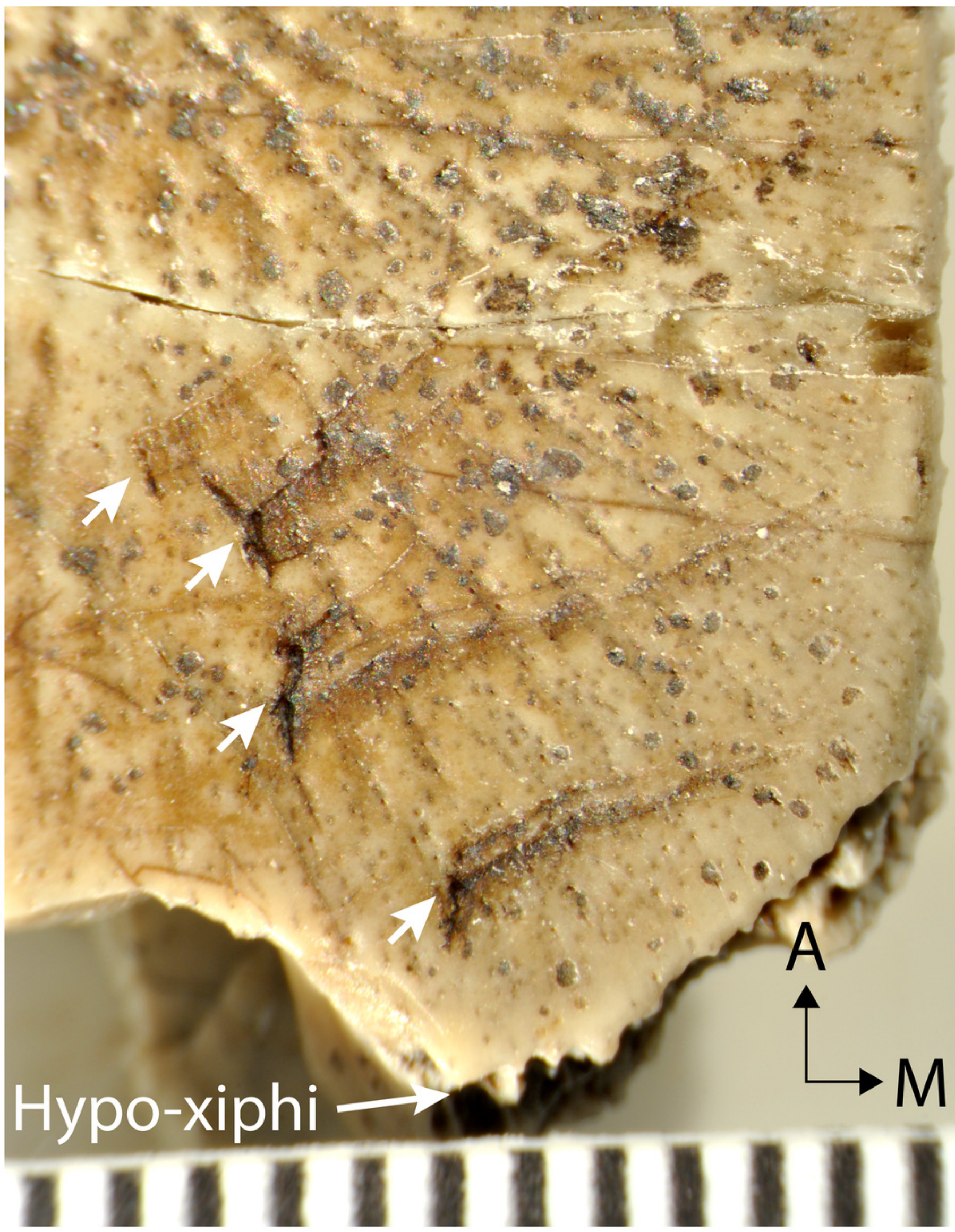




\section{Figure 6}

Associated carapace and plastron of Anosteira pulchra, specimen UMNH.VP.31072.

(A) Vertebral series and suprapygal in dorsal view. (B) Plastron and peripheral ring in dorsal view. (C) Vertebral series and suprapygal in ventral view. (D) Plastron and peripheral ring in ventral view. All parts of figure to same scale. Vertical blue lines indicate orientation of the midline. 

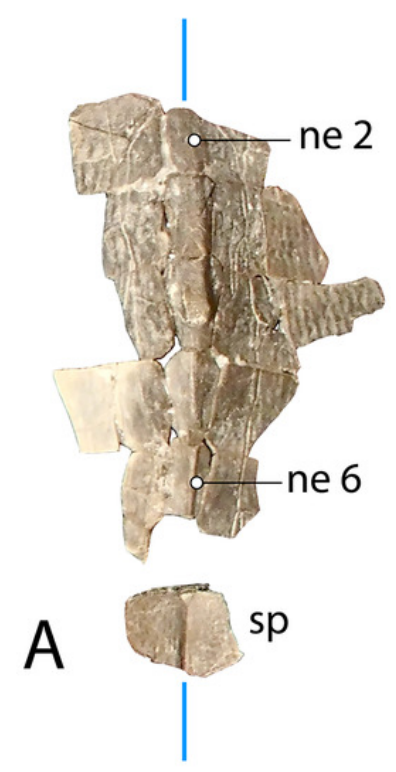
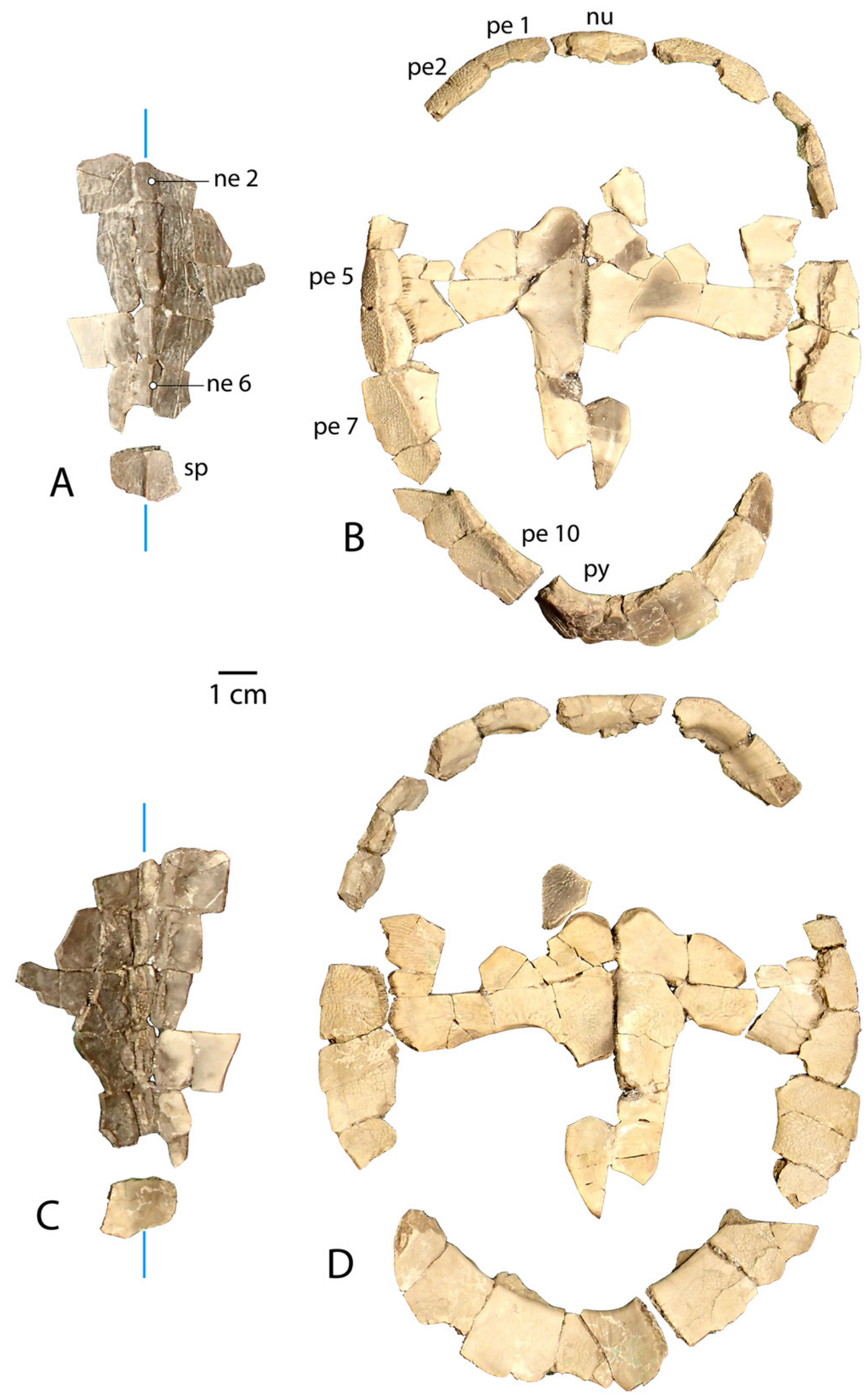


\section{Figure 7}

Scale pattern variation within Anosteira pulchra.

(A) Dorsal carapace of CM 11808, type specimen of A. pulchra. (B) Detail of carapacial scale pattern of CM 11808 as previously published (Clark, 1932), with yellow star indicating unmarked region of shell. (C) Dorsal carapace of YPM VPPU 16318, mentioned in Joyce (2014). (D) Detail of carapacial scale pattern of YPM VPPU 16318. (E) Dorsal carapace of YPM VPPU 16317, mentioned in Havlik, Joyce \& Böhme (2014) and Joyce (2014). (F) Detail of carapacial scale pattern of YPM VPPU 16317. (G) Partial carapace with scale pattern of UMNH.VP.27146. (H) Scale pattern of neural spike of larger individual in dorsolateral view of UMNH.VP.27453. (I) Scale pattern of third neural of smaller individual in dorsolateral view of UMNH.VP.27453. (J) Scale pattern of partial carapace of UMNH.VP.31072 in dorsal view. Red lines indicate sulci and black lines indicate sutures. Photos of YPM specimens courtesy of Yale Peabody Museum of Natural History (https://collections.peabody.yale.edu/search/). 

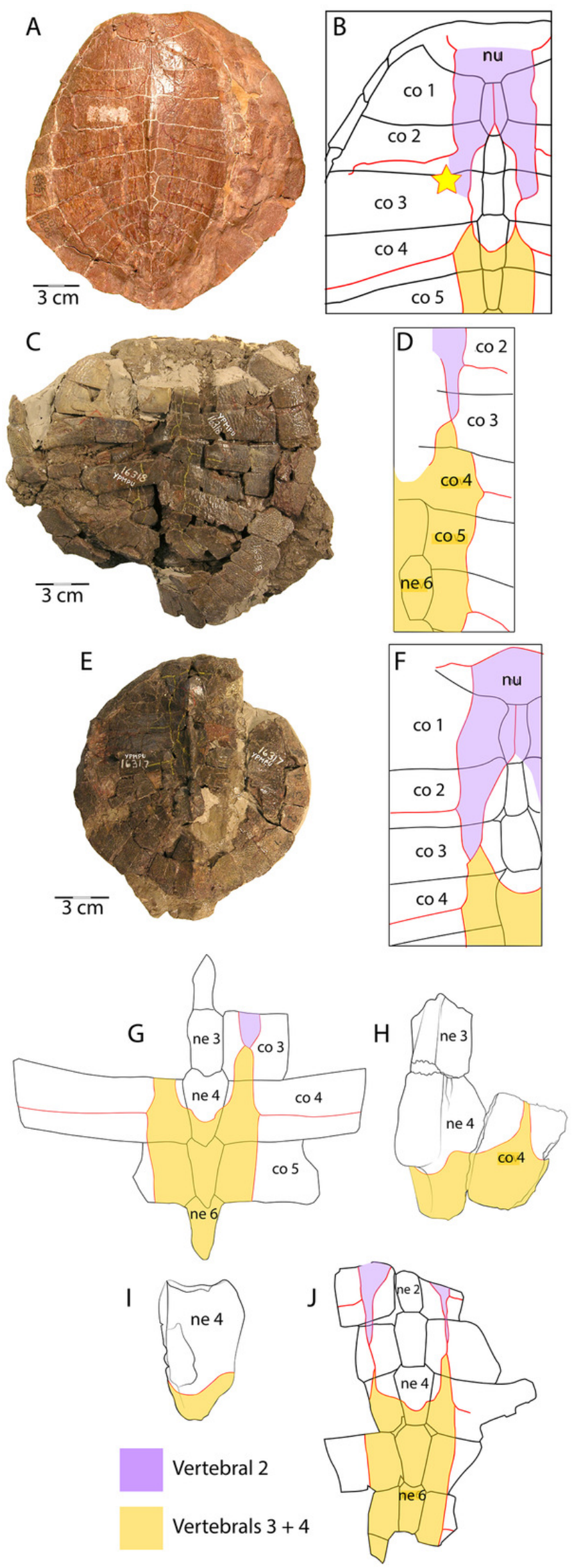